\title{
A chemogenomic approach seems indispensable for effective treatment of amyotrophic lateral sclerosis
}

\author{
Georgios Pampalakis ${ }^{1}$, Georgios Angelis ${ }^{1}$, Pinelopi Kastana ${ }^{2}$, Kostas Vekrellis ${ }^{3}$, and \\ Georgia Sotiropoulou² \\ ${ }^{1}$ Aristotle University of Thessaloniki \\ ${ }^{2}$ University of Patras \\ ${ }^{3}$ Biomedical Research Foundation of the Academy of Athens
}

January 29, 2021

\begin{abstract}
ALS is a fatal untreatable disease involving degeneration of motor neurons. Multiple causative genes encoding proteins with versatile functions have been identified indicating that diverse biological pathways lead to ALS. Gene and stem cell-based therapies are not expected to enter clinical practice anytime soon. Thus, chemical entities represent a promising choice to delay ALS progression, attenuate symptoms and/or increase life expectancy. Various compounds proved effective in transgenic models overexpressing distinct ALS causative genes but showed no efficacy in clinical trials. Notably, while animal models provide a uniform genetic background for preclinical testing, ALS patients are not stratified, and the distinct genetic forms of ALS are treated as a unique group which could explain the discrepancy between treating genetically homogeneous mice and quite heterogeneous patient cohorts. We suggest that chemical entity-genotype correlation should be exploited to guide patient stratification for therapy.
\end{abstract}

\section{A chemogenomic approach seems indispensable for effective treatment of amyotrophic lateral} sclerosis

Georgios Pampalakis $^{1 *}$, Georgios Angelis ${ }^{1}$, Pinelopi Kastana ${ }^{1}$, Kostas Vekrellis $^{2}$, Georgia Sotiropoulou ${ }^{3}$

${ }^{1}$ Department of Pharmacology-Pharmacognosy, School of Pharmacy, Aristotle University of Thessaloniki, Thessaloniki, 541 24, Greece

${ }^{2}$ Biomedical Research Foundation, Academy of Athens, 4 Soranou Ephessiou Str, 115 27, Athens, Greece

${ }^{3}$ Department of Pharmacy, School of Health Sciences, University of Patras, Rion-Patras, 265 04, Greece

${ }^{*}$ Corresponding author

Tel: 2310997638

E-mail: gpampalakis@pharm.auth.gr

Keywords

Amyotrophic lateral sclerosis (ALS); disease heterogeneity; small molecules; animal models; chemogenomics

Word count: 6478

Abstract 
ALS is a fatal untreatable disease involving degeneration of motor neurons. Multiple causative genes encoding proteins with versatile functions have been identified indicating that diverse biological pathways lead to ALS. Gene and stem cell-based therapies are not expected to enter clinical practice anytime soon. Thus, chemical entities represent a promising choice to delay ALS progression, attenuate symptoms and/or increase life expectancy. Various compounds proved effective in transgenic models overexpressing distinct ALS causative genes but showed no efficacy in clinical trials. Notably, while animal models provide a uniform genetic background for preclinical testing, ALS patients are not stratified, and the distinct genetic forms of ALS are treated as a unique group which could explain the discrepancy between treating genetically homogeneous mice and quite heterogeneous patient cohorts. We suggest that chemical entity-genotype correlation should be exploited to guide patient stratification for therapy.

\section{Introduction}

Amyotrophic lateral sclerosis (ALS) is a rare but rapidly progressive neurodegenerative disease with an estimated prevalence of 2:100,000. It is characterized by loss of motor neurons in the brain and spinal cord uniformly leading to death within 3-5 years from diagnosis most frequently due to respiratory paralysis (Brown and Al-Chalabi, 2017). Two ALS types can be distinguished, i.e. , familial ALS (FALS) that accounts for $5-10 \%$ of all ALS cases and sporadic ALS (SALS) that accounts for the rest. The hallmark of ALS is the abnormal accumulation of intracellular protein aggregates that vary in composition and could contain TDP-43, SOD1, FUS or various poly-dipeptides encoded by pathogenic GGGGCC expansions in the C9ORF72 gene. TDP-43 aggregates in the cytoplasm of neuronal cells are a common finding in ALS (especially SALS) patients except for patients that carry pathogenic variants in SOD1 (Blokhuis et al., 2013). Intriguingly though, pathogenic variants in $>30$ genes are responsible for ALS, without including disease modifier genes that significantly increase the heterogeneity of ALS (Pampalakis et al., 2019). Most commonly, mutations occur in C9ORF72, SOD1, TDP-43 and FUS genes underly respective FALS forms but are also found in many SALS cases (Zou et al., 2017). The underlying molecular complexity of SALS is further increased by various environmental factors (Hardiman et al., 2017) highlighted by studies of ALSPDC (amyotrophic lateral sclerosis-parkinsonism-dementia) prevalent in the pacific island of Guam, outlined below.

Riluzole (I ) and edaravone (II ) are the only drugs approved by the FDA for treatment of ALS, nevertheless, no significant improvement of disease or quality of life of ALS patients was observed by either of these drugs (Jaiswal, 2019; Mitropoulos et al., 2018). Stem cell therapies (Goutman et al., 2019), gene therapies (Cappella et al., 2019) and vaccinations (Zhou et al., 2020), are in early stages of development, thus, not expected to enter routine clinical practice in the near future. Consequently, there is a pressing need for chemical entities with pharmacological efficacy to attenuate disease symptoms and improve quality of life of ALS victims.

\section{The need for stratification of ALS patients}

Despite uniform clinical features in patients with established ALS, it is now understood that ALS is nothing but a homogenous disease (Swinnen and Robberecht, 2014) and most likely quite distinct biological pathways are involved, as also indicated by the functional versatility of the proteins encoded by pathogenetic variants of the identified familial ALS genes. The frequent failure of candidate compounds tested for ALS in clinical trials, which proved effective in animal models, could be explained by the fact that animal models represent a given ALS genotype, while clinical trials are conducted with non-stratified, thus, genetically heterogenous patient populations. Interrogation of the clinical trial database (http://clinicaltrials.gov) against "amyotrophic lateral sclerosis" retrieved 715 hits of which only 569 were related to ALS and the rest to SMA (spinal muscular atrophy). Of ALS trials, 146 involved the administration of 50 different small molecules but in only nine recent trials, patients were selected based on their involved ALS pathogenic gene. In the era of precision medicine, treatment decisions are guided by genetic/molecular data according to which patients are stratified into subgroups. The following two examples highlight the need for subgrouping ALS patients:

[1] ALS due to mercury intoxication. Incidentally, an SALS patient was identified who suffered ALS due to mercury intoxication and was treated with a combination of the chelator 2,3-dimercaptopropanesulfate and 
a-lipoic acid for mercury cleansing that was expected to ameliorate symptoms. In fact, this case turned to be the first reported ALS cure (Mangelsdorf et al., 2017). This is reminiscent of the loss of metal homeostasis reported in Alzheimer disease, for which either $\mathrm{Zn}^{2+}$ supplementation or $\mathrm{Fe}^{3+} / \mathrm{Al}^{3+}$ chelation therapies have been suggested (Adlard and Bush, 2018). Notably, metallomic analysis revealed uranium in the CSF of $47 \%$ of ALS patients examined in a Scandinavian study (Roos et al., 2013), suggesting that chelation treatment could be beneficial for this subgroup.

[2] The case of Guam - How changing diet can prevent ALS.In Guam, the incidence of ALS was unexpectedly high, i.e.approximately 200/100,000, making it a rather common neurodegenerative disease. Neurotoxin $\beta$-methylamino-L-alanine (L-BMAA) (III ), a component of cycad seeds consumed in Guam was identified as the ALS causing agent. Cycad seeds are consumed and bioaccumulated by flying foxes (bats) in the island which are popular food for locals. As a result, they intake large quantities of L-BMAA (Cox et al., 2003). Intravenous injection of L-BMAA induces ALS-PDC disease in rats that is accompanied by appearance of cytosolic TDP-43 aggregates (Tian et al., 2016). The incidence of ALS-PDC is constantly declining in Guam, following diet changes towards restricted bat consumption (Monson et al., 2003).

These two examples successfully demonstrate how the knowledge of the causative agent of ALS can lead to the design of successful targeted therapies and/or prevention measures.

\section{Therapeutic approaches based on the genetic background of ALS patients}

\section{Strategies to treat ALS caused by SOD1 pathogenetic variants}

$\mathrm{Tg}-S O D 1^{G 93 A}$ mice represent the first animal model for ALS and remains the most widely used rodent model of human ALS (Gurney et al., 1994). Chemicals that act on various biological pathways have been tested in these mice to investigate their putative effect on disease progression and overall survival. It is plausible though that the biological pathways in the ALS form recapitulated by $\mathrm{Tg}-S O D 1^{G 93 A}$ mice are not implicated in all ALS subtypes. The chemical compounds used to treat SOD1 -ALS can be classified based on their mechanism of action, as outlined below.

Reduction of excitotoxicity. Excitotoxicity describes the neuronal damage caused by excessive stimulation due to glutamate accumulation in the synaptic cleft. ALS patients and mouse models show decreased levels of the excitatory amino acid transporter 2 (EAAT2) that is responsible for synaptic glutamate clearance. Overexpression of $E A A T 2$ in $\mathrm{Tg}-S O D 1^{G 93 A}$ mice significantly delays grip strength decline but does not alter the onset of disease symptoms or the lifespan of Tg-EAAT2 /Tg-SOD1 ${ }^{G 93 A}$ mice compared to Tg-SOD1 ${ }^{\text {G93A }}$ (Guo et al., 2003) indicating that excitotoxicity may not represent an ideal target for pharmacological intervention in ALS. This is corroborated by clinical and preclinical data. For example, riluzole that inhibits the release of glutamate, extended the lifespan of ALS patients by only 2-3 months, while it had a modest effect in delaying disease progression (Contestabile, 2011). When administered at the onset of symptoms, it does not have any effect on lifespan or motor function of $\mathrm{Tg}-S O D 1^{G 93 A}, \mathrm{Tg}-T D P 43^{A 315 T}$ and Tg-FUS ${ }^{(1-359)}$ mouse models (Hogg et al., 2018). The efficacy of riluzole in patients may also be compromised by the rapid metabolism of the drug by CYP1A2. Thus, prodrugs that withstand CYP1A2 metabolism and have increased in vivo stability were designed (Limbert et al., 2013). Since serum levels of administered riluzole in patients are determined by the expression of CYP1A2 (Limbert et al., 2013), another way to increase the likelihood of response to riluzole could be to select ALS patients with low CYP1A2 levels.

Ceftriaxone (IV ), a cephalosporine antibiotic, that increases the activity of the EAAT2 gene promoter resulting in elevated EAAT2 expression that in turn reduces glutamate excitotoxicity (Cudkowicz et al., 2015), significantly improved the ALS phenotype of Tg-SOD1 ${ }^{G 93 A}$ mice and extended their lifespan by 10 days (Rothsein et al., 2005). Consistently, earlier case studies had reported improvement of symptoms in some ALS patients after administration of ceftriaxone (Smith, 1992). A later clinical trial (NCT00349622) showed no beneficial effect of ceftriaxone in non-stratified ALS patients. Whether SOD1 -ALS patients were included in this trial is unknown as no genetic data are available for retrospect analysis, to validate whether ceftiaxome was beneficial in this subgroup (Cudkowicz et al., 2015). 
Targeting inflammation. $\mathrm{TNF} \alpha$ is a major pro-inflammatory cytokine with a wide variety of biological responses including the apoptosis of neuronal cells. Increased levels of TNF $\alpha$ and FasL have been found in biopsy sections from lumbar spinal cord of ALS patients (FALS-SOD1 $1^{I 113 T}$ and SALS) and Tg-SOD1G93A mice (Kiaei et al., 2006). Thus, thalidomide (V ) and lenalidomide (VI ), which inhibit TNF $\alpha$ production, were tested in Tg-SOD ${ }^{G 93 A}$ mice. When administered pre-symptomatically, both compounds improved motor performance, attenuated weight loss and extended lifespan by approximately 3 weeks (16\% and $18.5 \%$ increase in mean survival, respectively) (Kiaei et al., 2006). When administered at the onset of symptoms, lenalidomide improved motor performance, weight loss and extended the lifespan of $\mathrm{Tg}$-SOD ${ }^{G 93 A}$ mice by approximately 19 days (Neymotin et al., 2009). A clinical trial with non-stratified ALS patients found that thalidomide does not improve the ALSFRS-R ( $A L S F$ unctional $R$ ating $S$ ystem- $R$ evised) score or the forced vital capacity (FVC) (Stommel et al., 2009). Thus, these compounds may only show effect inSOD1 -ALS given their beneficial effect in Tg-SOD $1^{G 93 A}$ mice. To this end, it is interesting to note that deletion of $T \nu \varphi a$ in $\mathrm{Tg}-S O D 1^{G 93 A}$ and $\mathrm{Tg}-S O D 1^{G 37 R}$ mice did not increase lifespan and did not inhibit the extent of neuronal loss (Gowing et al., 2006) indicating that thalidomide and lenalidomide may have other than $\mathrm{TNF} \alpha$-inhibiting (off-target) functions in vivo probably linked to the extended lifespan of Tg-SOD1G93A mice. Mapping the off-target effects in mice may reveal novel targets for pharmacological intervention. This endeavor could be accelerated or advanced by use of drug-based activity-based probes (ABPs) as will be described below.

Mitochondria targeting. Mitochondria dysfunction is a characteristic feature of ALS. Tg-SOD $1^{\text {G93A }}{ }^{\text {mice }}$ show decreased respiratory capacity in astrocytes. Dichloroacetate (DCA) (VII ) is a pyruvate dehydrogenase kinase inhibitor that stimulates mitochondrial metabolism and, when administered in drinking water of Tg$S O D 1^{G 93 A}$ mice, it extended their survival by 2 weeks in males and 10 days in females while it improved grip strength (Miquel et al., 2012).

Olesoxime (VIII ) is a mitochondrial pore modulator that reduces neuronal cell death in Tg-SOD1G93A mice (Sunyach et al., 2012) but a phase II/III clinical trial did not validate these positive effects in non-stratified ALS patients (Lenglet et al., 2014).

Coenzyme Q10 slightly increases the lifespan of Tg-SOD1 ${ }^{\text {G93A }}$ mice (Matthews et al., 1998), but a clinical trial with non-stratified ALS patients (NCT00243932) did not show phenotype improvement for a high dose of coenzyme Q10 (Kaufmann et al., 2009). Other dietary approaches to alleviate ALS symptoms have also been taken. The Deana Protocol Supplement involves arginine $\alpha$-ketoglutarate, $\gamma$-aminobutyric acid (GABA), coenzyme Q10 and medium chain triglycerides. When administered to ten-week-old Tg-SOD1 ${ }^{\text {G93A }}$ mice, this supplement improved survival and motor functions (Ari et al., 2014). Similarly, caprylic triglyceride which was used in a recent clinical trial (NCT02716662), enhanced motor performance in different tests, increased mitochondrial respiration compared to controls, but did not extend survival. Also, vitamin E delayed onset of disease symptoms in Tg-SOD $1^{G 93 A}$ mice but did not increase lifespan (Gurney et al., 1996). In a large clinical trial, high doses ( 5 g per day) of vitamin $\mathrm{E}$ did not have significant beneficial effects on survival or alleviation of symptoms (Graf et al., 2005). The SS31 antioxidant peptide improved survival and motor performance in $T g$-SOD $1^{G 93 A}$ mice and reduced cell apoptosis due to hydrogen peroxide in vitro (Petri et al., 2006) but it has not yet been validated in clinical trials. Since all these studies showed effectiveness of the aforementioned supplements in $\mathrm{Tg}$-SOD $1^{G 93 A}$ their therapeutic effect may be limited to SOD1 -ALS patients.

Rasagiline (IX ), a MAO-B inhibitor that has antioxidant and anti-apoptotic functions extends the lifespan and improves the running wheel performance of $\mathrm{Tg}-S O D 1^{G 93 A}$ mice. Co-administered with riluzole, it showed additive effects in Tg-SOD1 ${ }^{G 93 A}$ mice (Waibel et al., 2004). Currently, rasagiline is being tested in ALS patients of various disease genotypes (NCT01879241, NCT01786603), with positive results in reducing oxidative stress in mitochondria, and increasing the mitochondrial membrane potential (Macchi et al., 2015).Dexpramipexole (X ), a dopamine receptor antagonist, had protective effects in vitro manifested by improved mitochondrial function, prevented apoptosis, and reduced ROS (Cheah et al., 2010) but failed to exhibit positive results in $\mathrm{Tg}-S O D 1^{G 93 A}$ mice and, in a phase III clinical trial in ALS patients (Wilkins et 
al., 2017).

Targeting SOD1 aggregation. Formation of SOD1 aggregates can be suppressed by either inhibiting SOD1 aggregation directly or by reducing the expression of SOD1 (Limpert et al., 2013), as for example with pyrimethamine. In SOD1 -ALS patients, pyrimethamine lowers the levels of SOD1 in CSF (Lange et al., 2017). This clinical trial was designed to specifically include SOD1 -ALS patients and to monitor the levels of SOD1 in CSF (NCT01083667).

Another strategy involves the stabilization of SOD1 dimers to diminish the formation of aggregates through chemical crosslinking between adjacent $\mathrm{Cys}^{111}$ of two SOD1 molecules with maleimide derivatives and thioldisulfide exchange approaches, e.g., with 1,4-bismaleimidobutane (Auclair et al., 2010).

A recent strategy involves targeting the interaction between SOD1 and derlin-1, which plays a role in endoplasmic reticulum (ER) machinery and disrupting this interaction has a positive role in alleviating ALS symptoms (Tsuburaya et al., 2018). High-throughput screening (HTS) identified compound XI that prevents the interaction of mutant SOD1 with derlin-1. A series of analogues were synthesized andXII with better physicochemical properties was tested as a candidate drug. XII alleviated pathology of Tg-SOD1 ${ }^{\text {G93A }}$ mice and of motor-neurons derived from iPSC of patients with SOD1 -ALS (Tsuburaya et al., 2018).

Screening of $640 \mathrm{FDA}$ approved drugs found that statins (simvastatin, lovastatin, mevastatin) and vitamin D3 derivatives (alfacalcidol, calcidiol, calcitriol) inhibited aggregation of apo-SOD1 ${ }^{\mathrm{G} 37 \mathrm{R}}$ (Anzai et al., 2016). Unexpectedly, statins accelerate disease progression, decrease the lifespan of $T g$-SOD ${ }^{G 93 A}$ mice (Su et al., 2016) and worsen the phenotype of ALS patients manifested by increased rates of ALSFRS-R decline and higher frequency of muscle cramps (Zinman et al., 2008). These observations uncover obstacles of HTS against pure components like the SOD1 aggregates to identify new drugs, but vitamin D3 supplementation in Tg-SOD $1^{G 93 A}$ mice improves motor function (Gianforcaro and Hamadeh, 2014). Nevertheless, although earlier studies showed that patient intake of vitamin D3 slowed the rate of ALSFRS-R decline (Karam et al., 2013), later studies did not replicate these findings (Trojsi et al., 2019; Libonati et al., 2017). These contradictory clinical evidences may be due to the quite varying genetic background of patients.

Ebselen (XIII ) is an organoselenium cysteine reactive compound that assists in the formation of the intramolecular disulfide bond of SOD1 and its correct folding. Thus, it facilitates the production of the functional SOD1 dimer instead of the toxic aggregates. In addition, ebselen has antioxidant activity (Capper et al., 2018). Although it only marginally extended the lifespan of Tg-SOD1 ${ }^{G 93 A}$ mice it significantly delayed the onset of disease symptoms (Amporndanai et al., 2020). Thus, it may alleviate the symptoms in SOD1 -ALS patients.

In analogous manner, treatment with $\mathrm{Cu}(\mathrm{II}) \mathrm{ASTM}$ (XIV ) improves symptoms and extends survival in TgSOD ${ }^{G 93 A}$ (Hilton et al., 2017) and Tg-SOD1 ${ }^{G 37 R}$ mice (Roberts et al., 2014). A mechanism accounting for its function involves copper transfer to SOD1. Thus, the loading of SOD1 with metal ions may provide a new type for SOD1 -ALS specific therapy. A phase I clinical trial to assess the pharmacokinetics of Cu(II)ASTM in ALS patients has been completed (NCT02870634) and another study (NCT04082832) is ongoing to assess its efficacy without, however, selecting for SOD1 -ALS patients in which drug efficacy has been proven.

Finally, pyrazolone derivatives have been identified as SOD1 aggregation inhibitors (Zhang et al., 2015; Chen et al., 2011) and the pyrazolone $\mathbf{X V}$ increased the lifespan of $\mathrm{Tg}-S O D 1^{G 93 A}$ by $13 \%$ (Chen et al., 2012). In this case, an activity-based probe (ABP) was designed to map its complete interactome (i.e. biological targets and off-targets). For this, a biotin moiety with a spacer was introduced to one side of the molecule and the new derivative (XVI ) was immobilized on streptavidin beads. The beads were incubated with cellular lysates and the precipitants were analyzed by mass spectrometry to identify the biological targets (Trippier et al., 2014). This assay revealed an unexpected function of pyrazolones, i.e ., proteosomal activation without heat shock response.

Targeting proteolysis. Biochemical pathways involving proteases may provide novel targets for ALS treatment. In this respect, the widely studied metalloprotease MMP9 mediates the degeneration of fast motor 
neurons in Tg-SOD1 ${ }^{\text {G93A }}$ mice through enhancement of ER stress (Kaplan et al., 2014) and/or regulation of Tnf $\alpha$ and FasL expression (Kiaei et al. 2007). Deletion of one Mmp9 allele in Tg-SOD1 ${ }^{G 93 A}$ increased the lifespan by $14 \%$ while deletion of both alleles ( $\mathrm{Tg}-\mathrm{SOD} 1^{G 93 A} \mathrm{Mmp}^{-{ }^{--}}$) by $25 \%$, which is the longest prolongation of lifespan ever reported for an intervention in any of ALS mouse models. Intracerebroventricular (icv) administration of an MMP9 inhibitor in Tg-SOD1G93A mice delayed denervation and reduced ER stress (Kaplan et al., 2014). Knockdown or knockout of MMP9 attenuates the neuromuscular defects in rNLS8 (Tg-T $\Delta \Pi-43 \Delta N \Lambda \Sigma$ ) mice. Intriguingly though, Tg- $T \Delta \Pi-43 \Delta N \Lambda \Sigma M \mu \pi 9^{-/}$-mice have significantly shortened survival and run slower than the rNLS8, despite their attenuated neuromuscular defects (Spiller et al., 2019). Thus, targeting MMP9 for inhibition may represent a beneficial therapeutic strategy only for SOD1 -ALS patients.

Maintenance of proteostasis. The dynamic regulation of a balanced, functional proteome (proteostasis) orchestrates multiple cellular systems and functions like the ubiquitin proteasome system, autophagy, ER stress/unfolded protein response, stress granules and heat shock proteins, to provide "quality control" for proteome maintenance. The proteostasis drug methylene blue (XVII) that induces autophagy (Congdon

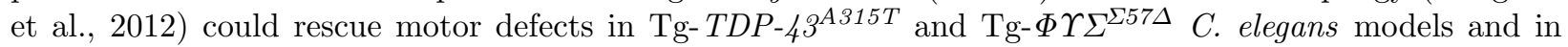
$\mathrm{Tg}-T D P-43^{G 348 C}$ and Tg-FUS ${ }^{521 H} D$. rerio (Vaccaro et al., 2012) but not in $T g$ - TDP-43 ${ }^{G 348 C}$ (Audet et al., 2012) and Tg-SOD1G93A mice (Lougheed and Turnbull, 2011). These results indicate that selection of the appropriate animal model is essential for extrapolating animal data to putative clinical significance.

Sephin 1 (XVIII) is a selective inhibitor of the stress-induced phosphatase PPP1R15A that prolongs eIF2 phosphorylation upon stress and protects cells from ER stress. In Tg-SOD1G93A mice, sephin 1 prevents weight loss and improves motor function (Das et al., 2015).

Another approach to target SOD1 -ALS involves the activation of heat shock family chaperones that protect cells from various stresses. Arimoclomol (XIX ), a heat shock protein inducer, delays onset of symptoms, extends the lifespan, promotes muscle function, and prevents the aggregation of SOD1 in Tg-SOD1 G93A mice (Kieran et al., 2004; Kalmar et al., 2012). In the clinical trial NCT00706147, rapidly progressive SOD1 -mutant ALS patients were treated with up to $200 \mathrm{mg}$ arimoclomol and this phase II trial showed that arimoclomol is safe and well-tolerated (Benatar et al., 2018). An ongoing phase III clinical trial (NCT03836716) with 231 participants aims to define the long-term safety and efficacy of arimoclomol inSOD1-ALS patients.

\section{Targeting $\mathrm{G}_{4} \mathrm{C}_{2}$ pathogenetic expansions in C9ORF72}

The GGGGCC large repeat expansions (from 250 up to $>3000$ repeats) present in the first intron of the C9ORF72 gene have been identified in patients suffering from ALS or FTD (frontotemporal dementia) (Dejesus-Hernandez et al., 2011; Renton et al., 2011). These hexanucleotide expansions are transcribed bidirectionally and form either RNA foci in the nucleus, that binds and sequesters RNA-binding proteins, or are translated into dipeptide repeat proteins (DPRs) by an abnormal translation process called repeatassociated non-ATG (RAN) translation (Jiang et al., 2019). This results in gain-of-function that leads to neuronal cell toxicity (Jiang et al., 2019). These GGGGCC repeats exhibit somatic instability, thus, it is possible that repeat expansion may not be present in DNA from blood samples although present in CNS. Therefore, a blood test negative for GGGGCC expansion does not necessarily indicate that the patient is not a C9ORF $72^{E x p G G G G C C}$ carrier, and this should be taken into consideration when classifying ALS patients. Evidently, a combination of genetic analysis and determination of poly-(GP) in CSF will be required for a definite clinical diagnosis (Balendra et al., 2017; Lehmer et al., 2017). Approaches to alleviate symptoms or decelerate the course of the disease include targeting the RNA transcribed from GGGGCC-repeats or targeting the DPRs. These RNAs adopt two folded states that are in equilibrium, a hairpin structure and the G-quadruplex structure (Su et al., 2014).

Targeting RNA G-quadruplexes/hairpins. HTS identified the structurally similar chemicals DB1246 (XX ), DB1247 (XXI ), and DB1273 (XXII ), that exhibit high-affinity binding on GGGGCC RNA G-quadruplexes. These chemicals significantly reduced RNA foci in vitro in human iPSC-motor and iPSCcortical neuron cell lines and decreased DPRs. Decreased levels of DPRs and improved survival of larvae 
reaching the pupal stage of development was observed in vivo , in GGGGCC repeat-expressing Drosophilastreated with DB1273 (Simone et al., 2018).

The cationic porphyrin (5,10,15,20-tetra(N-methyl-4-pyridyl) porphyrin (TMPyP4)) XXIII binds to GGGGCC RNA G-quadruplexes in a concentration-dependent manner and causes a conformational change in their secondary structures conferring thermal instability of GGGGCC RNA G-quadruplexes. Thus, TMPyP4 blocks the interaction of GGGGCC RNA G-quadruplexes with RNA-binding proteins, such as ASF/SF2 and hnRNPA1 (Zamiri et al., 2014). Another group developed three compounds (XXIV , XXV , XXVI ) targeting the hexanucleotide repeat region of RNAs and tested them for binding to hairpin RNA and reducing RAN in a cell-free model. XXIV andXXV reduced RNA foci and significantly decreased RAN translation in GGGGCC repeat-expressing neurons (Su et al., 2014). Improving the selectivity of XXIV , led to compoundXXVII that binds selectively in the internal loops of the hairpin form of RNA. XXVII blocked polysome assembly and reduced RNA foci and RAN translation in vitro (Wang et al., 2019). The in vivo action of these compounds inC9ORF72 -ALS remains to be validated.

Targeting DPRs. RAN translation of C9ORF72 RNA GGGGCC-repeats in all six-reading frames produces five repeated polypeptides $[\operatorname{poly}(\mathrm{GA})$, poly $(\mathrm{GP})$, poly $(\mathrm{GR})$, poly $(\mathrm{PR})$, and poly $(\mathrm{PA})]$ that are toxic to cells through induction of nucleolar stress and defects in mRNA splicing (Mori et al., 2013a; Mori et al., 2013b).

Inhibition of PIKFYVE kinase that converts phosphatidylinositol-3-phosphate (PI3P) to phosphatidylinositol-3,5-biphosphate [PI $(3,5) \mathrm{P} 2]$ leads to increased PI3P levels that regulate autophagosome formation and engulfment of proteins for degradation. Therefore, it may be important for the destruction of DPRs. Indeed, the PIKFYVE inhibitor apilimod (XXVIII ) reduces DPRs in C9-BAC mice that harbor the human C9ORF72 with 100-1000 GGGGCC repeats (Staats et al., 2019).

Another way to reduce protein aggregates, including DPRs, is through proteosome activation. Rolipram (XXIX) is an antidepressant drug that acts via inhibition of phosphodiesterase 4 (PDE4) and promotes proteasome function. Rolipram decreased poly $(\mathrm{GA})$ in primary hippocampal neurons in vitro (Khosravi et al., 2020). DPRs induce integrated stress response (ISR) through ER implicating TMX2(Kramer et al., 2018). ISR involves hyperphosphorylation of elf2a and increased RAN of C9ORF"2 RNA GGGGCC-repeats (Cheng et al., 2018).XXX , a selective inhibitor of eIF $2 \alpha$ dephosphorylation and tauroursodeoxycholate (TUDCA), a chemical chaperone, showed protection against poly(GA)-induced stress and cell death in vitro (Zhang et al., 2014). In conclusion, there are many compounds that can target the DPRs that need to be evaluated in animal models and then in clinical trials.

\section{Targeting TDP-43 pathogenic variants}

Transactive response DNA binding protein 43 (TDP-43) is primarily a nuclear protein that binds to UG/TG repeats in the introns of pre-mRNA (Xiao et al., 2011) and regulates transcription or RNA processing (Polymenidou et al. 2012). Under stress conditions, TDP-43 is found in stress granules inside the cell (Colombrita et al., 2009). These cytoplasmic aggregates consist of full-length TDP-43 or of its C-terminal proteolytic fragments of 35 and $25 \mathrm{kDa}$ (Hergesheimer et al., 2019). Further, cytoplasmic TDP-43 is mainly ubiquitinated and phosphorylated in ALS patients (Neumann et al., 2006).

Targeting autophagy or proteasome. TDP-43 regulates the production of ATG7, an autophagy mediator, by stabilizing the $A T G 7$ mRNA. Thus, depletion of TDP-43 causes loss of ATG7 and impaired autophagy (Bose et al., 2011). Furthermore, loss of TDP-43 increases TFEB nuclear translocation and enhances autophagosomal and lysosomal biogenesis but it impairs fusion of autophagosomes with lysosomes (Xia et al., 2016). Consequently, TDP-43 aggregation observed in ALS could lead to dysregulation of autophagy. In addition, the $25 \mathrm{kDa}$ TDP-43 fragment causes severe cognitive and behavioral deficits in mice, and suppression of autophagy and proteasome activation (Caccamo et al., 2015).

Inhibitors of mTOR act as activators of autophagy through induction of autophagosome formation (Zarogoulidis et al., 2014). Administration of the autophagy activators rapamycin, spermidine, carbamazepine 
and tamoxifen in a mouse model of ALS/FTD with TDP-43 aggregates decreased the loss of motor neurons and TDP-43 aggregates (Wang et al., 2012). Rapamycin also increased the lifespan of a Drosophila ALS/FTD model (Cheng et al., 2015). In contrast, in $\mathrm{Tg}-S O D 1^{G 93 A}$ mice, rapamycin decreased survival and induced mitochondrial dysfunction and cell death in cultured motor neurons isolated from these animals (Zhang et al., 2011). The above data further support the hypothesis that different therapies should be used for different ALS subtypes.

A HTS study found fluphenazine (FPZ), methotrimeprazine (MTM) and 10-(4'-(N-diethyl amino)butyl)-2chlorophenoxazine (NCP) as the most potent autophagy activators. When neuronal and astrocyte ALS cell models were treated with these chemicals, the levels of TDP-43 aggregates were reduced, cell survival was improved and decreased nuclear-cytoplasmic shuttling was observed (Barmada et al., 2014).

Phosphorylation of TDP-43. Casein kinase 1 (CK-1), cell division cycle 7 (CDC7), tau and tubulin kinase 1 and 2 (TTBK1 and TTBK2, respectively), and mitogen-activated protein kinases (MAPK/ERK) phosphorylate TDP-43 that in turn promotes the aggregation in the cytoplasm (Palomo et al., 2019). Nilotinib (XXXI ) and bosutinib (XXXII ), two tyrosine kinase inhibitors (TKI), altered glutamate synaptic signal-

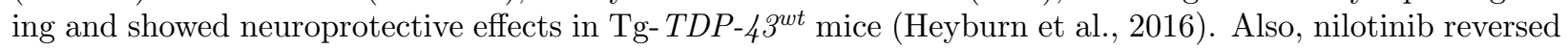
mitochondrial dysfunction caused by TDP-43 aggregates (Heyburn et al., 2016). In addition, bosutinib increased survival of iPSC-derived motor neurons from patients with SALS or FALS caused by mutations in TDP-43 or GGGGCC repeat expansions in C9ORF72 while it delayed disease onset in Tg-SOD1G93A for 11 days and moderately increased survival by 8 days (Imamura et al., 2017). In conclusion, TKIs may provide a more general therapeutic strategy for ALS since they showed clinical efficacy in genetically diverse ALS models.

A series of $N$-(benzothiazolyl)-2-phenyl-acetamide compounds were developed and optimized for CK-1 inhibition. The compoundXXXIII exhibited the lowest $\mathrm{IC}_{50}$ of $23 \mathrm{nM}$, while the XXXIV had an $\mathrm{IC}_{50}$ of $47 \mathrm{nM}$ and both could penetrate the blood brain barrier (BBB). XXXIII decreased phosphorylation of TDP-43 and increased the lifespan of the Tg-TDP-43 Drosophila (Salado et al., 2014). Both XXXIIIand XXXIV prevented TDP-43 phosphorylation and nucleus-cytoplasm shuttling in PGRN -(progranulin) deficient lymphoblasts (Alquezar et al., 2016) and in lymphoblasts from SALS patients (negative for SOD1 pathogenetic variants and one positive for expansions in C9ORF72 ) (Posa et al., 2018). The CDC7 selective inhibitor PHA767491 (XXXV) abolished phosphorylated forms of TDP-43 in vitro and in vivo in $C$. elegans (Liachko et al., 2013), indicating a possible target against pathological phosphorylation of TDP-43.

Targeting stress granules. Screening of 35 kinase inhibitors against paraquat-treated SH-SY5Y cells identified inhibitors of cyclin-dependent kinases (CDKs) and glycogen synthase kinase 3 (GSK3) to block TDP-43 accumulation in stress granules, thus alleviating intracellular cell stress (Moujalled et al., 2013). Another chemical discovered by HTS, the LDN-0130436 (XXXVI), improved the motor behavioral deficits of Tg-TDP-43 $3^{w t}$ and Tg-TDP-43A315T C. elegans (Boyd et al., 2014).

Other compounds. Various attempts aimed to identify compounds that may display therapeutic effect in TDP-43-ALS. In a screening of 1,200 FDA-approved drugs, the PPAR $\gamma$ agonist pioglitazone was identified to improve the locomotor function of Tg- TDP-43 $3^{w t}$ or $T g-T D P-43^{G 298 S}$ Drosophilas, yet it did not improve the survival of flies (Joardar et al., 2015). Unfortunately, when pioglitazone was used in an ALS clinical trial in combination with riluzole (NCT00690118), it did not increase patient survival neither it improved any of the clinical symptoms (Dupuis et al., 2012). Failure of pioglitazone may be related to the fact that it either acts on certain ALS subtypes or the above-mentioned Drosophila models do not recapitulate the corresponding human ALS subtypes. This resembles the already mentioned case of methylene blue that displays pharmacological activity in C. elegans models of ALS but not in mouse models.

Anacardic acid (XXXVII) acts as a histone acetyltransferase inhibitor and decreases TDP-43 mRNA and protein levels in human iPSCs derived from ALS patients carrying TDP-43 pathogenetic variants (Egawa et al., 2012). A different strategy for treating TDP-43 associated ALS involves targeting nuclear exportins that control TDP-43 nucleus-to-cytoplasm shuttling. TDP-43 has a nuclear export signal (NES) recognized 
by XPO1. The selective inhibitor of nuclear export (SINE) that targets XPO1, KPT-350 (XXXVIII ) partially rescues the motor deficits in a rat model of ALS/FTD generated by adenoviral delivery of TDP-43 (Archbold et al., 2018).

\section{FUS mutations}

The treatment of the subpopulation of patients with FUS -ALS is currently based on autophagy induction and alleviation of oxidative stress. Torkinib (XXXIX ) inhibition of mTOR induces autophagy more potently than rapamycin and reduces TDP- $43^{\mathrm{P} 525 \mathrm{~L}}$ aggregates in engineered iPSC-derived spinal neurons induced by arsenite. Torkinib, improved dose-dependently the motor neuron dysfunction in three FUS Drosophila models (FUS ${ }^{\mathrm{wt}}$, FUS ${ }^{\mathrm{R} 521 \mathrm{C}}$, FUS ${ }^{\mathrm{P} 525 \mathrm{~L}}$ ) measured with the climbing assay (Marrone et al., 2019). Mutant FUS-aggregates are localized in stress granules and stimulating autophagy with rapamycin decreases FUS in these granules (Ryu et al., 2014). Furthermore, mutant FUS is implicated in the first stages of autophagosome formation and Rab1 overexpression restores autophagy function (Soo et al., 2015). In a controlled ongoing clinical trial (NCT03707795), betamethasone is used in ALS patients withFUS mutations to alleviate oxidative stress and improve symptoms.

\section{Pharmacological modulation of gene modifiers}

Modifier gene alleles either exacerbate or attenuate the clinical presentation of ALS (Table 1). The identification and characterization of modifier genes is an ongoing endeavor that could provide new therapeutic options for certain ALS subgroups (Yanagi et al. 2019). Ephrin A4 (EPHA4) is a well-established ALS gene modifier (Van Hoecke et al., 2012). Loss-of-function mutations in EPHA 4 associate with longer survival of ALS patients and different ALS animal models (Table 1). Thus, pharmacological inhibition of EPHA4 could provide a new way to treat ALS. In this direction, the 4-(2,5-dimethyl-1H-pyrrol-1-yl)-2-hydroxy benzoic acid (XL ), a pharmacological inhibitor of EphA4 (Noberini et al., 2008), rescues mutant SOD1 induced axonopathy in zebrafish (Van Hoecke et al., 2012). The compound 123C4 (XLI ) is an EphA4 receptor binding agent that prolongs survival of $\mathrm{Tg}-S O D 1^{G 93 A}$ mice by 8.5 days (Wu et al., 2017). EPHA4 can be considered a "universal" ALS gene modifier since it acts as modulator for both SOD1 and TDP-43 associated ALS. However, administration of antisense oligonucleotides targeting EphA 4 did not affect motor function or survival of Tg-SOD1 ${ }^{G 93 A}$ or Tg- $P F N 1^{G 118 V}$ mice, although it significantly delayed (from 154 to 199 days) the onset of symptoms in Tg-PFN1 ${ }^{G 118 V}$ (Ling et al., 2018). The success of chemical targeting of EphA4 to prolong survival in animal models over oligonucleotide targeting could be related to the fact that the former study targeted both the CNS and periphery, while oligonucleotides administered icv targeted only the CNS.

Lithium carbonate $\left(\mathrm{Li}_{2} \mathrm{CO}_{3}\right)$ increased the 12-month survival probability of ALS patients bearing the $U C N 13 A \mathrm{C} / \mathrm{C}$ polymorphism. Thus, lithium carbonate may be used only for this patient subgroup (van Eijk et al., 2017). Another well-described ALS gene modifier is CX3CR1 (Lopez-Lopez et al., 2014). Deletion of $C x 3 c r 1$ in $\mathrm{Tg}-S O D 1^{G 93 A}$ mice reduced lifespan, increased neuronal loss and SOD1 aggregation (Liu et al., 2019).

Another ALS gene modifier with potential pharmacological application is the $I L 6 R \mathrm{C}$ allele that results in the substitution D358A in the interleukin 6 receptor. IL6R C ALS carriers have increased levels of IL6 and soluble IL6R in serum and CSF and accelerated disease progression rates (Wosiski-Kuhn et al., 2019), nevertheless, deletion of $I l 6$ in Tg-SOD1 ${ }^{G 93 A}$ did not alter the lifespan (Han et al., 2016). Administration of tocilizumab, a humanized monoclonal antibody against IL6R, in SALS patients displaying strong expression of inflammatory genes in peripheral blood mononuclear cells (PBMCs), attenuated clinical symptoms. In contrast, administration of tocilizumab in SALS patients with weak inflammatory gene expression upregulated the inflammatory reaction (Fiala et al., 2013). Whether anti-IL6R therapies may be more effective in IL6R $C$ carriers with no SOD1 mutations remains to be investigated.

\section{Antiretrovirals therapy for ALS}

In the 1990s, antibodies against foamy viruses were detected in serum of SALS patients (Alfahad and Nath, 2013) and a clinical study was initiated to treat SALS patients positive for antibodies against the foamy 
virus human spuma retrovirus (HSRV), with zidovudine, though it showed no clinical benefit (Westarp et al., 1993). Later, the implication of HSRV in ALS patients was challenged (Rosener et al., 1998) and currently foamy viruses are not considered to participate in ALS (Alfahad and Nath, 2013).

Human endogenous retroviruses (HERV) represent approximately $8 \%$ of the human genome. They are divided into three classes I, II and III based on tRNA-primer binding site. HERV-K elements belong to class II carrying a complete ORF for gag, pol and env and can produce virus-like particles (Griffiths, 2001). Expression of HERV-K was found in a subgroup of ALS patients (Mayer et al., 2018; Douville et al., 2011). TDP-43 regulates the expression of HERV-K through binding to the long terminal repeats of the retrovirus (Li et al., 2015). Theenv viral protein is probably responsible for ALS symptoms since transgenic mice expressing the env gene under a neuronal specific promoter show loss of upper and lower motor neurons (Li et al., 2015). Approved anti-HIV reverse transcriptase inhibitors block the replication of HERV-K viral particles by inhibiting the HERV-K reverse transcriptase (Contreras-Galindo et al., 2017; Tyagi et al., 2017), while the integrase inhibitor raltegravir could also block HERV-K viral particle replication (Tyagi et al., 2017). Based on these data, in terms of the ongoing clinical trial (NCT02437110), ALS patients with elevated (>1000 copies/ml) HERV-K levels are treated with a combination of four anti-HIV drugs, darunavir, ritonavir, dolutegravir, tenofovir alafenamide. Thus, this study has been designed based on molecular analysis of ALS patients and its completion will define the role of endogenous retroviruses in ALS. The presented ALS subgroups and the compounds that can be directed for their specific treatment are summarized in Figure 1.

\section{Design of new clinical trials}

The genetic background of ALS patients has not been taken into consideration when designing clinical trials, except of those trials which involved oligonucleotide drugs that by default target mutated genes, thus DNA analysis is indispensably required for patient selection. Specifically, the clinical trial NCT02623688 with the antisense drug targeting SOD1 tofersen (BIIB067) enrolls only patients with confirmed SOD1 mutations, while the NCT03626012 that involves the BIIB078 targeting C9ORF72 will enroll only C9ORF72 -ALS patients. However, few recent clinical trials with synthetic drug compounds have been designed to enroll ALS patients of a specific genetic background. Arimoclomol (XIX ) was found to improve muscle strength and prolong survival of $\mathrm{Tg}-S O D 1^{G 93 A}$ mice by increasing the expression of heat shock protein 70 (Kalmar et al., 2008; Kieran et al., 2004). The clinical trial NCT00706147 with arimoclomol included only patients with confirmed SOD1 mutations. Arimoclomol was safe and well-tolerated and further studies are needed to evaluate the therapeutic benefit (Benatar et al., 2018). In the same context, a clinical trial with pyrimethamine (XLII) for FALS with SOD1 mutations to determine the safety and tolerability was performed (NCT01083667). Further, a metformin (XLIII ) clinical trial for treatment ofC9ORF72 ALS patients (NCT04220021) is now recruiting patients. This was based on the fact that although metformin has no beneficial effect in the phenotype of $\mathrm{Tg}-S O D 1^{G 93 A}$ mice (Kaneb et al., 2011), in C9-ALS/FTD mice it mitigated disease symptoms (Zu et al., 2020).

Colchicine - An example of genetic analysis to exclude FALS patients. Colchicine is an antiinflammatory drug that can also induce the expression of heat shock protein B8 (HSPB8) that enhances autophagy to remove TDP-43 of SOD1 misfolded proteins or C9ORF72 -related aggregated poly-dipeptides (Mandrioli et al., 2019; Crippa et al., 2016). An ongoing clinical trial for SALS patients (NCT03693781) excludes patients with mutations in SOD1, TDP-43 ,FUS and C9ORF72 (Mandrioli et al., 2019).

Retrospective analysis of outcomes of clinical trials. These studies could reveal relations between chemical treatment and genetic background. In some new clinical trials, ALS patients are screened for certain mutations by DNA sequencing. In certain clinical trials, patients have provided blood samples for future DNA analysis that could be exploited in retrospective studies. Creatine is a representative example. Initially creatine administration to ALS patients did not show any improvement of clinical symptoms (Groeneveld et al., 2003). However,post hoc analysis of clinical data and genetic background of patients showed that ALS patients with $\mathrm{A} / \mathrm{A}$ and $\mathrm{A} / \mathrm{C}$ polymorphisms in $M O B P$ gene will benefit for creatine treatment (Van Eijk et al., 2019). In the same direction, a meta-analysis of clinical trials that used lithium carbonate in ALS showed 
that lithium carbonate increased the 12-month survival probability from $40 \%$ to $70 \%$ in patients that carry the C/C polymorphism in UNC13A, while no effect inC9ORF72 carriers (Van Eijk et al., 2017).

\section{Target identification using genetically engineered models}

Genetic ablation or transgenic studies on the Tg-SOD1 ${ }^{G 93 A}$ background may unravel new targets for ALS treatment but may not always be of direct clinical relevance since genetic modification has already taken place at the embryo stage and well-before disease symptoms appear. Drugs are administered when diagnosis has been made, that for ALS may take up to 12 months after the appearance of symptoms. In this sense, a marginal effect on symptoms or life extension after deletion of a gene in an ALS mouse model could indicate that pharmacological targeting of the gene-encoded protein will not be effective in patients. Inducible knockout models or inducible transgenic models on an ALS background (e.g.Tg-SOD1 ${ }^{G 93 A}$ ) will provide a more sophisticated practice to search for relevant pharmacological targets since it will allow genetic modification to take place after the appearance of symptoms. In this direction, it has been demonstrated that reduction ofEPHA4 in adulthood does not affect survival of Tg-SOD1 ${ }^{G 93 A}$ mice (Rué et al., 2019). Thus, chemical targeting of EPHA4 after the onset of symptoms may not delay disease progression. Finally, extrapolation of animal data to humans should be made in a very cautious manner since mouse models may not recapitulate human ALS, thus some compounds that were found effective in treating mice may not be beneficial to patients. Nevertheless, this problem may be more pronounced when extrapolating data from more distant drosophila and zebrafish.

\section{Conclusions}

Current clinical and experimental data cumulatively suggest that it is unlikely that a "universal" ALS drug will be effective in ALS patients. In contrast, different subtypes of ALS patients will require different drug treatment strategies according to the suggested chemogenomic approach. In this direction, the use of animal models for testing drugs against a certain genetic background or the re-evaluation of already completed animal and/or clinical studies is of great importance. As elaborated here, the extrapolation of preclinical data to patients should be performed cautiously since evolutionary distant models such as drosophila and $C$. elegans may provide false findings regarding the efficacy of a drug, in contrast to mice. It is known that the genome and the networks of functional connectivity are significantly different between the more evolutionary distant animals and these could significantly affect the biological outcome of pharmacological treatment. Other factors should also be taken into consideration when evaluating preclinical data, e.g. in many preclinical studies, treatment was initiated before the onset of symptoms, which cannot be applied to ALS patients. Currently, diagnosis of ALS takes almost a year since it relies only on the assessment of the clinical status, the electrophysiological examination, and progressive exclusion of other pathologies. Nonetheless, the clinical benefit of riluzole is higher when administered early in the course of the disease (Zoing et al., 2006). Thus, early diagnosis will enhance therapeutic efficacy. For this, molecular diagnosis of ALS is urgently needed in clinics (Pampalakis et al., 2019). If early drug treatment is combined with patient subgrouping/stratification, it is expected to further extend the clinical benefits of the tested compounds.

\section{Acknowledgement}

This project has received funding from the Hellenic Foundation for Research and Innovation (HFRI) and the General Secretariat for Research and Innovation (GSRI), under grant agreement No 1876.

\section{Figure legends}

Figure 1. Genotype-based classification of described ALS subtypes and representative targets and compounds for corresponding patient subtypes.

Table 1. Gene modifiers for ALS 


\begin{tabular}{|c|c|c|c|c|}
\hline$\overline{\text { Gene }}$ & Effect on ALS & Method/Model & Subtype of ALS & Reference \\
\hline EPHA4 & $\begin{array}{l}\text { Survival, onset Loss } \\
\text { of function increases } \\
\text { survival Mice, } \\
\text { zebrafish, patients } \\
\text { Pharmacological } \\
\text { inhibition increases } \\
\text { survival Loss of } \\
\text { function mutations } \\
\text { long survival }\end{array}$ & 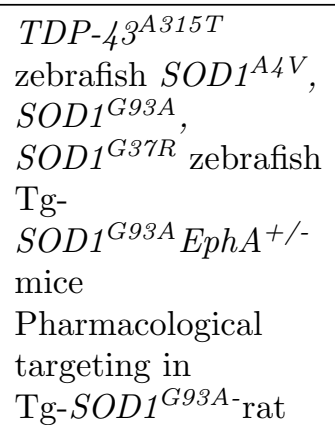 & TDP-43, SOD1 & $\begin{array}{l}\text { Van Hoecke et al., } \\
2012\end{array}$ \\
\hline EPHA4 & Extends survival & $\begin{array}{l}\text { Pharmacological } \\
\text { targeting in } \\
\text { Tg-SOD1 } \\
\text { mice }\end{array}$ & SOD1 & Wu et al., 2017 \\
\hline EPHA4 & Delays onset & $\begin{array}{l}\text { Tg-PFN1 }{ }^{G 118 V} \\
\text { mice }\end{array}$ & PFN & Ling et al. 2018 \\
\hline$C X 3 C R 1$ & Survival & Patients & & $\begin{array}{l}\text { Lopez-Lopez et } \\
\text { al., } 2014\end{array}$ \\
\hline CXЗ $C R 1$ & $\begin{array}{l}\text { Survival, } \\
\text { knockout reduces } \\
\text { survival }\end{array}$ & $\begin{array}{l}\mathrm{Tg} S O D 1^{G 93 A} \\
C x 3 \mathrm{cr}^{-/-} \text {mice }\end{array}$ & SOD1 & Liu et al., 2019 \\
\hline$I L 6 R$ & $\begin{array}{l}\mathrm{C} \text { variant } \\
\text { Asp358Ala } \\
\text { Increased rate of } \\
\text { progression }\end{array}$ & Patients & & $\begin{array}{l}\text { Wosiski-Kuhn et al., } \\
2019\end{array}$ \\
\hline KCNJ11 & Survival & $\begin{array}{l}\text { Patients Rs5219 } \\
\text { increased survival in } \\
\text { bulbar ALS, } \\
\text { patients with } \mathrm{T} / \mathrm{T} \\
\text { survived longer }\end{array}$ & & $\begin{array}{l}\text { Vidal-Taboada et } \\
\text { al., } 2018\end{array}$ \\
\hline$A B C C 8$ & Survival & $\begin{array}{l}\text { Patients Rs4148646 } \\
\text { increased survival in } \\
\text { bulbar ALS patients } \\
\text { with G/G survived } \\
\text { longer, Rs4148642 } \\
\text { In spinal ALS } \\
\text { patients with C/C } \\
\text { have increased } \\
\text { progression rate }\end{array}$ & & $\begin{array}{l}\text { Vidal-Taboada et } \\
\text { al., } 2018\end{array}$ \\
\hline$U N C 13 A$ & $\begin{array}{l}\text { Survival Regulates } \\
\text { neurotransmitter } \\
\text { release }\end{array}$ & $\begin{array}{l}\text { Patients } \\
\text { Rs12608932 shorter } \\
\text { survival }\end{array}$ & & Diekstra et al., 2012 \\
\hline
\end{tabular}

\section{References}

Adlard, P.A.; Bush, A.I. Metals and Alzheimer's disease: how far have we come in the clinic? J. Alzheimers Dis. , 2018 , 62 , 1369-1379.

Alfahad, T.; Nath, A. Retroviruses and amyotrophic lateral sclerosis.Antiviral Res. , 2013 , 99 , 180-187.

Alquezar, C.; Salado, I.G.; de la Encarnación, A., Pérez, D.I.; Moreno, F.; Gil, C.; de Munain, A.L.; Martínez, 
A.; Martín-Requero, Á. Targeting TDP-43 phosphorylation by Casein Kinase-1ס inhibitors: a novel strategy for the treatment of frontotemporal dementia. Mol. Neurodegener. ,2016 , 11, 36.

Ampornadai, K.; Rogers, M.; Watanabe, S.; Yamanaka, K.; O’Neill, P.M.; Hasnain, S.S. Novel seleniumbased compounds with therapeutic potential for SOD1-linked amyotrophic lateral sclerosis. EBioMedicine ,2020, 59,102980 .

Anzai, I.; Toichi, K.; Tokuda, E.; Mukaiyama, A.; Akiyama, S.; Furukawa, Y. Screening of drugs inhibiting in vitro oligomerization of $\mathrm{Cu} / \mathrm{Zn}$-superoxide dismutase with a mutation causing amyotrophic lateral sclerosis. Front. Mol. Biosci. , 2016 , 3 , 40.

Archbold, H.C.; Jackson, K.L.; Arora, A.; Weskamp, K.; Tank, E.M.; Li, X.; Miguez, R.; Dayton, R.D.; Tamir, S.; Klein, R.L.; Barmada, S.J. TDP43 nuclear export and neurodegeneration in models of amyotrophic lateral sclerosis and frontotemporal dementia. Sci. Rep. ,2018 , 8, 4606.

Ari, C.; Poff, A.M.; Held, H.E.; Landon, C.S.; Goldhagen, C.R.; Mavromates, N.; D'Agostino, D.P. Metabolic therapy with Deanna Protocol supplementation delays disease progression and extends survival in amyotrophic lateral sclerosis (ALS) mouse model. PLoS One ,2014, 9 , e103526.

Auclair, J.R.; Boggio, K.J.; Petsko, G.A.; Ringe, D.; Agar, J.N. Strategies for stabilizing superoxide dismutase (SOD1), the destabilized in the most common form of familial amyotrophic lateral sclerosis.Proc. Natl. Acad. Sci. USA, 2010, 107, 21394-21399.

Audet, J.N.; Soucy, G.; Julien, J.P. Methylene blue administration fails to confer neuroprotection in two amyotrophic lateral sclerosis mouse models. Neuroscience, 2012, 209 , 136-143.

Balendra, R.; Moens, TG.; Isaacs, A.M. Specific biomarkers for C9orf72 FTD/ALS could expedite the journey towards effective therapies.EMBO Mol. Med. , 2017, 7 , 853-855.

Barmada, S.J.; Serio, A.; Arjun, A. Autophagy induction enhances TDP43 turnover and survival in neuronal ALS models. Nat. Chem. Biol. ,2014, $10,677-685$.

Benatar, M.; Wuu, J.; Andersen, P.M.; Atassi, N.; David, W.; Cudkowicz, M.; Schoenfeld, D. Randomized, double-blind, placebo-controlled trial of arimoclomol in rapidly progressive SOD1 ALS. Neurology,2018 , 90 , e565-e574.

Blokhuis, A.M.; Groen, E.J.; Koppers, M.; van den Berg, L.H.; Pasterkamp, R.J. Protein aggregation in amyotrophic lateral sclerosis. Acta Neuropathol. , 2013 , 125 , 777-794.

Bose, P.; Tremblay, E.; Maois, C.; Narasimhan, V.; Armstrong, G.A.B.; Liao, M.; Parker, J.A.; Robitaille, R.; Wen, X.Y.; Barden, C.; Drapeau, P. The novel small molecule TRVA242 stabilizes neuromuscular junction defects in multiple animal models of amyotrophic lateral sclerosis.Neurotherapeutics , 2019 , 16 , 1149-1166.

Boyd, J.D.; Lee, P.; Feiler, M.S.; Zauur, N.; Liu, M.; Concannon, J.; Ebata, A.; Wolozin, B.; Glicksman, M.A. A high-content screen identifies novel compounds that inhibit stress-induced TDP-43 cellular aggregation and associated cytotoxicity. J. Biomol. Screen. , 2014,19 , 44-56.

Brown, R.H.; Al-Chalabi, A. Amyotrophic Lateral Sclerosis. N. Engl. J. Med. , 2017 , 377 , 162-172.

Caccamo, A.; Shaw, D.M.; Guarino, F.; Messina, A.; Walker, A.W.; Oddo, S. Reduced protein turnover mediates functional deficits in transgenic mice expressing the $25 \mathrm{kDa}$ C-terminal fragment of TDP-43. Hum. Mol. Genet. , 2015, 24 , 4625-4635.

Cappella, M.; Ciotti, C.; Cohen-Tannoudji, M.; Biferi, M.G. Gene therapy for ALS-a perspective. Int. J. Mol. Sci. , 2019 ,20 , E4388.

Capper, M.J.; Wright, G.S.A.; Barbieri, L.; Luchinat, E.; Mercatelli, E.; McAlary. L.; Yerbury, J.J.; O’Neil, P.M.; Antonyuk, S.V.; Banci, L.; Hasnain, S.S. The cysteine-reactive small molecule ebselen facilitates effective SOD1 maturation. Nat. Commun., 2018, 9 , 1693. 
Cheah, B.C.; Kiernan. M.C. Dexpramipexole, the R(+) enantiomer of pramipexole, for the potential treatment of amyotrophic lateral sclerosis. IDrugs , 2010 , 13, 911-920.

Chen, T.; Benmohamed, R.; Arvanites, A.C.; Ralay Ranaivo, H.; Morimoto, R.I.; Ferrante, R.J.; Watterson, D.M.; Kirsch, D.R.; Silverman, R.B. Arylsuflanyl pyrazolones block mutant SOD1-G93A aggregation. Potential application for the treatment of amyotrophic lateral sclerosis.Bioorg. Med. Chem. , 2011 , 19 , 613-622.

Chen, T.; Benmohamed, R.; Kim, J.; Smith, K.; Amante, D.; Morimoto, R.I.; Kirsch, D.R.; Ferrante, R.J.; Silverman, R.B. ADME-guided design and synthesis of aryloxanyl pyrazolone derivatives to block mutant superoxide dismutase 1 (SOD1) cytotoxicity and protein aggregation: potential application for the treatment of amyotrophic lateral sclerosis. J. Med. Chem., 2012, 55 , 515-527.

Cheng, C.W.; Lin. M.J.; Shen, C.K. Rapamycin alleviates pathogenesis of a new Drosophila model of ALS-TDP. J. Neurogenet. , 2015 ,29, 59-68.

Cheng, W.; Wang, S.; Mestre, A.A.; Fu, C.; Makarem, A.; Xian, F.; Hayes, L.R.; Lopez-Gonzalez, R.; Drenner, K.; Jiang, J.; Cleveland, D.W.; Sun, S. C9ORF72 GGGGCC repeat-associated non-AUG translation is upregulated by stress through eIF2 $\alpha$ phosphorylation. Nat. Commun. ,2018, 9,51 .

Colombrita, C.; Zennaro, E.; Fallini, C. TDP-43 is recruited to stress granules in conditions of oxidative insult. J. Neurochem. ,2009 , 111, 1051-1061.

Congdon, E.E.; Wu, J.W.; Myeku, N.; Figueroa, Y.H.; Herman, M.; Marinec, P.S.; Gestwicki, J.E.; Dickey, C.A.; Yu, W.H.; Duff, K.E. Methylthioninium chloride (methylene blue) induces autophagy and attenuates tauopathy in vitro and in vivo. Autophagy ,2012, $8,609-622$.

Contestabile, A. Amyotrophic lateral sclerosis: from research to therapeutic attempts and therapeutic perspectives. Curr. Med. Chem., 2011, 18 , 5655-5665.

Contreras-Galindo, R.; Dube, D.; Fujinaga, K.; Kaplan, M.H.; Markovitz, D.M. Susceptibility of human endogenous retrovirus type K to reverse transcriptase inhibitors. J. Virol. , 2017 , 91 , e01309.

fCox, P.A.; Banack, S.A.; Murch, S.J. Biomagnification of cyanobacterial neurotoxins and neurodegenerative disease among the Chamorro people of Guam. Proc. Natl. Acad. Sci. USA , 2003 , $100,13380-13383$.

Crippa, V.; D’ Agostino, V.G.; Cristofani, R.; Rusmini, P.; Cicardi, M.E.; Messi, E.; Loffredo, R.; Pancher, M.; Piccolella, M.; Galbiati, M.; Meroni, M.; Cereda.; Carra, S.; Provenzani, A.; Poletti, A. Transcriptional induction of the heat shock protein B8 mediated the clearance of misfolded proteins responsible for motor neuron diseases.Sci. Rep. , 2016 , 6 , 22827.

Cudkowicz, M.E.; Titus, S.; Kearney, M.; Yu, H.; Sherman, A.; Schoenfeld, D.; Hayden, D.; Shui, A.; Brooks, B.; Conwit, R.; Felsenstein, D.; Greenblatt, D.J.; Keroack, M.; Kissel, J.T.; Miller, R.; Rosenfeld, J.; Rothstein, J.; Simpson, E.; Tolkoff-Rubin, N.; Zinman, L.; Shefner, J.M. Efficacy and safety of ceftriaxone for amyotrophic lateral sclerosis: results of a multi-stage, randomized, double-blind, placebo-controlled, phase 3 study. Lancet Neurol. ,2015, 13 , 1083-1091.

Das, I.; Krzyzosiak, A.; Schneider, K.; Wrabetz, L.; D’ Antonio, M.; Barry, N.; Sigurdardottir, A.; Bertolotti, A. Preventing proteostasis diseases by selective inhibition of a phosphatase regulatory subunit.Science, 2015 , 348, 239-242.

DeJesus-Hernandez, M.; Mackenzie, I.R.; Boeve, B.F.; Boxer, A.L.; Baker, M.; Rutherford, N.J.; Nicholson, A.M.; Finch, N.A.; Flynn, H.; Adamson, J.; Kouri, N.; Wojtas, A.; Sengdy, P.; Hsiung, G.Y.; Karydas, A.; Seeley, W.W.; Josephs, K.A.; Coppola, G.; Geschwind, D.H.; Wszolek, Z.K.; Feldman, H.; Knopman, D.S.; Petersen, R.C.; Miller, B.L.; Dickson, D.W.; Boylan, K.B.; Graff-Radford, N.R.; Rademakers, R. Expanded GGGGCC hexanucleotide repeat in noncoding region of C9ORF72 causes chromosome 9p-linked FTD and ALS. Neuron, 2011, 72 , 245-256. 
Diekstra, F.P.; van Vught, P.W.J.; van Rheenen, W.; Koppers, M.; Pasterkamp, R.J.; van Es, M.A.; Schelhaas, H.J.; de Visser, M.; Robberecht, W.; Van Damme, P.; Andersen, P.M.; van den Berg, L.H.; Veldink, J,H. UNC13A is a modifier of survival in amyotrophic lateral sclerosis. Neurobiol. Aging, 2012, 33, 630.

Douville, R.; Liu, L.; Rothstein, J.; Nath, A. Identification of active loci of a human endogenous retrovirus in neurons of patients with amyotrophic lateral sclerosis. Ann. Neurol. , 2011,69 , 141-151.

Dupuis, L.; Dengler, R.; Heneka, M.T.; Meyer, T.; Zierz, S.; Kassubek, J.; Fischer, W.; Steiner, F.; Lindauer, E.; Otto, M.; Dreyhaupt, J.; Grehl, T.; Hermann, A.; Winkler, A.S.; Bogdahn, U.; Benecke, R.; Schrank, B.; Wessig, C.; Grosskreutz, J.; Ludolph, A.C.; GERP ALS Study Group. (2017) A randomized, double blind, placebo-controlled trial of pioglitazone in combination with riluzole in amyotrophic lateral sclerosis. PLoS One, 2017, 7 , e37885.

Egawa, N.; Kitaoka, S.; Tsukita, K.; Naitoh, M.; Takahashi, K.; Yamamoto, T.; Adachi, F.; Kondo, T.; Okita, K.; Asaka, I.; Aoi, T.; Watanabe, A.; Yamada, Y.; Morizane, A.; Takahashi, J.; Ayaki, T.; Ito, H.; Yoshikawa, K.; Yamawaki, S.; Suzuki, S.; Watanabe, D.; Hioki, H.; Kaneko, T.; Makioka, K.; Okamoto, K.; Takuma, H.; Tamaoka, A.; Hasegawa, K.; Nonaka, T.; Hasegawa, M.; Kawata, A.; Yoshida, M.; Nakahata, T.; Takahashi, R.; Marchetto, M.C.; Gage, F.H.; Yamanaka, S.; Inoue, H. Drug screening for ALS using patient-specific induced pluripotent stem cells.Sci. Transl. Med. , 2012 , 4 , $145 \mathrm{ra104.}$

Fiala, M.; Mizwicki, M.T.; Weitzman, R.; Magpantay, L.; Nishimoto, N. Tocilizumab infusion therapy normalizes inflammation in sporadic ALS patients. Am. J. Neurodegener. Dis., 2013, 2 , 129-139.

Gianforcaro, A.; Hamadeh, M.J. Vitamin D as a potential therapy in amytrophic lateral sclerosis. CNS Neurosci. Ther. , 2014 ,20 , 101-111.

Goutman, S.A.; Savelieff, M.G.; Sakowski, S.A.; Feldman, E.L. Stem cell treatments for amyotrophic lateral sclerosis: a critical overview of early phase trials. Expert Opin. Investig. Drugs , 2019 ,28, 525-543.

Gowing, G.; Dequen, F.; Soucy, G.; Julien, J.P. Absence of tumor necrosis factor- $\alpha$ does not affect motor neuron disease caused by superoxide dismutase 1 mutations. J. Neurosci. , 2006 ,26 , 11397-11402.

Graf, M.; Ecker, D.; Horowski, R.; Kramer, B.; Riederer, P.; Gerlach, M.; Hager, C.; Ludolph, A.C.; Becker, G.; Osterhage, J.; Jost, W.H.; Schrank, B.; Stein, C.; Kostopulos, P.; Lubik, S.; Wekwerth, K.; Dengler, R.; Troeger, M; Wuerz, A.; Hoge, A.; Schrader, C.; Schimke, N.; Krampfl, K.; Petri, S.; Zierz, S.; Eger, K.; Neudecker, S.; Traufeller, K.; Sievert, M.; Neundörfer, B.; Hecht, M.; German vitamin E/ALS Study Group. High dose vitamin E therapy in amyotrophic lateral sclerosis as add-on therapy to riluzole: results of a placebo-controlled double-blind study. J. Neural. Transm. , 2005 , 112 , 649-660.

Griffiths, D.J. Endogenous retroviruses in the human genome sequence.Genome Biol. , 2001 , 2 , REVIEWS1017.

Groeneveld, G.J., Veldink, J.H.; van der Tweel, I.; Kalmijn, S.; Beijer, C.; de Visser M.; Wokke, J.H.J.; Franssen, H.; van den Berg, L.H. A randomized sequential trial of creatine in amyotrophic lateral sclerosis. Ann. Neurol., 2003, 53 , 437-445

Guo, H.; Lai, L.; Butchbach, M.E.; Stockinger, M.P.; Shan, X.; Bishop, G.A.; Lin, C.L. Increased expression of the glial glutamate transporter EAAT2 modulates excitoxicity and delays the onset but not the outcome of ALS in mice. Hum. Mol. Genet. , 2003 , 12 , 2519-2532.

Gurney, M.E.; Cutting, F.B.; Zhai, P.; Doble, A.; Taylor, C.P.; Andrus, P.K.; Hall, E.D. Benefit of vitamin $\mathrm{E}$, riluzole, and gabapentin in a transgenic model of familial amyotrophic lateral sclerosis. Ann. Neurol. , $1996,39,147-157$.

Gurney, M.E.; Pu, H.; Chiu, A.Y.; Dal Canto, M.C.; Polchow, C.Y.; Alexander, D.D.; Caliendo, J.; Hentati, A.; Kwon, Y.W.; Deng, H.X. Motor neuron degeneration in mice that express a human $\mathrm{Cu}$, Zn superoxide dismutase mutation. Science, 1994, 264, 1772-1775. 
Han, Y.; Ripley, B.; Serada, S.; Naka, T.; Fujimoto, M. Interleukin-6 deficiency does not affect motor neuron disease caused by superoxide dismutase 1 mutation. PLOS One, 2016 , 11, e0153399.

Hardiman, O.; Al-Chalabi, A.; Chio, A.; Corr, E.M.; Logroscino, G.; Robberecht, W.; Shaw, P.J.; Simmons, Z.; van den Berg, L.H. Amyotrophic lateral sclerosis. Nat. Rev. Dis. Primers , 2017 ,3 , 17071.

Hergesheimer, R.C.; Chami, A.A.; de Assis, D.R. The debated toxic role of aggregated TDP-43 in amyotrophic lateral sclerosis: a resolution in sight? Brain , 2019 , 142 , 1176-1194.

Heyburn, L.; Hebron, M.L.; Smith, J.; Winston, C.; Bechara, J.; Li, Z.; Lonskaya, I.; Burns, M.P.; Harris, B.T.; Moussa, C.E. Tyrosine kinase inhibition reverses TDP-43 effects on synaptic protein expression, astrocytic function and amino acid dis-homeostasis. J. Neurochem., 2016 , 139 , 610-623.

Hilton, J.B.; Mercer, S.W.; Lim, N.K.; Faux, N.G.; Buncic, G.; Beckman, J.S.; Roberts, B.R.; Donnelly, P.S.; White, A.R.; Crouch, P.J. CuII(atsm) improves the neurological phenotype and survival of SOD1G93A mice and selectively increases enzymatically active SOD1 in the spinal cord. Sci. Rep. , 2017 , 7 , 42292.

Hogg, M.C.; Halang, L.; Woods, I.; Coughlan, K.S.; Prehn, J.H.M. Riluzole does not improve lifespan or motor function in three ALS mouse models. Amyotroph. Lateral Scler. Frontotemporal Degener. ,2018 , 19 , 438-445.

Imamura, K.; Izumi, Y.; Watanabe, A.; Tsukita, K.; Woltjen, K.; Yamamoto, T.; Hotta, A.; Kondo, T.; Kitaoka, S.; Ohta, A.; Tanaka, A.; Watanabe, D.; Morita, M.; Takuma, H.; Tamaoka, A.; Kunath, T.; Wray, S.; Furuya, H.; Era, T.; Makioka, K.; Okamoto, K.; Fujisawa, T.; Nishitoh, H.; Homma, K.; Ichijo, H.; Julien, J.P.; Obata, N.; Hosokawa, M.; Akiyama, H.; Kaneko, S.; Ayaki, T.; Ito, H.; Kaji, R.; Takahashi, R.; Yamanaka, S.; Inoue, H. The Src/c-Abl pathway is a potential therapeutic target in amyotrophic lateral sclerosis. Sci. Transl. Med. ,2017, 9, eaaf3962.

Jaiswal, M.K. Riluzole and edaravone: a tale of two amyotrophic lateral sclerosis drugs. Med. Res. Rev. , $\mathbf{2 0 1 9}, 39,733-748$.

Jiang, J.; Zhu, Q.; Gendron, T.F.; Saberi, S.; McAlonis-Downes, M.; Seelman, A.; Stauffer, J.E.; Jafar-Nejad, P.; Drenner, K.; Schulte, D.; Chun, S.; Sun, S.; Ling, S.C.; Myers, B.; Engelhardt, J.; Katz, M.; Baughn, M.; Platoshyn, O.; Marsala, M.; Watt, A.; Heyser, C.J.; Ard, M.C.; De Muynck, L.; Daughrity, L.M.; Swing, D.A.; Tessarollo, L.; Jung, C.J.; Delpoux, A.; Utzschneider, D.T.; Hedrick, S.M.; de Jong, P.J.; Edbauer, D.; Van Damme, P.; Petrucelli, L.; Shaw, C.E.; Bennett, C.F.; Da Cruz, S.; Ravits, J.; Rigo, F.; Cleveland, D.W.; Lagier-Tourenne, C. Gain of Toxicity from ALS/FTD-Linked Repeat Expansions in C9ORF72 Is Alleviated by Antisense Oligonucleotides Targeting GGGGCC-Containing RNAs. Neuron, 2016 , 90 , 535-550.

Joardar, A.; Menzl, J.; Podolsky, T.C. PPAR gamma activation is neuroprotective in a Drosophila model of ALS based on TDP-43. Hum. Mol. Genet. , 2015 , 24 , 1741-1754.

Kalmar, B.; Edet-Amana, E.; Greensmith, L. Treatment with a coinducer of the heat shock response delays muscle denervation in the SOD1-G93A mouse model of amyotrophic lateral sclerosis. Amyotroph. Lateral Scler. , 2012, 13, 378-392.

Kalmar, B.; Novoselov, S.; Gray, A.; Cheetham, M.E.; Margulis, B.; Greensmith, L. Late stage treatment with arimoclomol delays disease progression and prevents protein aggregation in the SOD193A mouse model of ALS. J. Neurochem. , 2008 , 102, 339-350.

Kaneb, H.M.; Sharp, P.S.; Rahmani-Kondori, N.; Wells, J. Metformin treatment has no beneficial effect in a dose-response survival study in the SOD1G93A mouse model of ALS and is harmful in female mice.PLoS One, 2011, 6 , e24189.

Kaplan, A.; Spiller, K.J.; Towne, C.; Kanning, K.C.; Choe, G.T.; Geber, A.; Akay, T.; Aebischer, P.; Henderson, C.E. Neuronal matrix metalloproteinase-9 is a determinant of selective neurodegeneration.Neuron , 2014, $81,333-348$. 
Karam, C.; Barrett, M.J.; Imperato, T.; MacGowan, D.J.L.; Scelsa, S. Vitamin D deficiency and its supplementation in patients with amyotrophic lateral sclerosis. J. Clin. Neurosci., 2013 ,20 , 1550-1553.

Kaufmann, P.; Thompson, J.L.; Levy, G.; Buchsbaum, R.; Shefner, J.; Krivickas, L.S.; Katz, J.; Rollins, Y.; Barohn, R.J.; Jackson, C.E.; Tiryaki, E.; Lomen-Hoerth, C.; Armon, C.; Tandan, R.; Rudnicki, S.A.; Rezania, K.; Sufit, R.; Pestronk, A.; Novella, S.P.; Heiman-Patterson, T.; Kasarskis, E.J.; Pioro, E.P.; Montes, J.; Arbing, R.; Vecchio, D.; Barsdorf, A.; Mitsumoto, H.; Levin, B.; QALS Study Group. Phase II trial of CoQ10 for ALS finds insufficient evidence to justify phase III.Ann. Neurol. , 2009 , 66 , 235-244.

Khosravi, B.; LaClair, K.D.; Riemenschneider, H.; Zhou, Q.; Frottin, F.; Mareljic, N.; Czuppa, M.; Farny, D.; Hartmann, H.; Michaelsen, M.; Arzberger, T.; Hartl, F.U.; Hipp, M.S.; Edbauer, D. Cell-to-cell transmission of C9orf72 poly-(Gly-Ala) triggers key features of ALS/FTD.EMBO J. , 2020 , 16 , e102811.

Kiaei, M.; Kipiani, K.; Calingasan, N.Y.; Wille, E.; Chen, J.; Heissig, B.; Rafii, S.; Lorenzl, S.; Beal, M.F. Matrix metalloproteinase-9 regulates TNF-alpha and FasL expression in neuronal, glial cells and its absence extends life in a transgenic mouse model of amyotrophic lateral sclerosis. Exp. Neurol., 2007 , 205 , 74-81.

Kiaei, M.; Petri, S.; Kipiani, K.; Gardian, G.; Choi, D.K.; Chen, J.; Calingasan, N.Y.; Schafer, P.; Muller, G.W.; Stewart, C.; Hensley, K.; Beal, M.F. Thalidomide and lenalidomide extend survival in a transgenic mouse model of amyotrophic lateral sclerosis. Neurobiol. Aging ,2006 , 26 , 2467-2473.

Kieran, D.; Kalmar, B.; Dick, J.R.T.; Riddoch-Contreras, J.; Burnstock, G.; Greensmith, L. Treatment with arimoclomol, a coinducer of heat shock proteins, delays disease progression in ALS mice. Nat. Med. ,2004, $10,402-405$.

Kramer, N.J.; Haney, M.S.; Morgens, D.W.; Jovičić, A.; Couthouis, J.; Li, A.; Ousey, J.; Ma, R.; Bieri, G.; Tsui, K.; Shi, Y.; Hertz, N.T.; Tessier-Lavigne, M.; Ichida, J.K., Bassik, M.C.; Gitler, A.D. CRISPR-Cas9 screens in human cells and primary neurons identify modifiers of C9ORF72 dipeptide-repeat-protein toxicity. Nat. Genet. , 2018, 50, 603-612.

Lange, D.J.; Shahbazi, M.; Silani, V.; Ludolph, A.C.; Weishaupt, J.H.; Ajroud-Driss, S.; Fields, K.G.; Remanan, R.; Appel, S.H.; Morelli, C.; Doretti, A.; Maderna, L.; Messina, S.; Weiland, U.; Marklund, S.L.; Andersen, P.M. Pyrimethamine significantly lowers cerebrospinal fluid $\mathrm{Cu} / \mathrm{Zn}$ superoxide dismutase in amyotrophic lateral sclerosis with SOD1 mutations. Annals Neurol. , 2017 , 81 , 837-848.

Lehmer, C.; Oeckl, P.; Weishaupt, J.H.; Volk, A.E.; DiehlSchmid, J.; Schroeter, M.L.; Lauer, M.; Kornhuber, J.; Levin, J.; Fassbender, K.; Landwehrmeyer, B.; German Consortium for Frontotemporal Lobal Degeneration; Schludi, M.H.; Arzberger, T.; Kremmer, E.; Flatley, A.; Feederle, R.; Steinacker, P.; Weydt, P.; Ludolph, A.C.; Edbauer, D.; Otto, M. Poly-GP in cerebrospinal fluid links C9orf72-associated dipeptide repeat expression to the asymptomatic phase of ALS/FTD.EMBO Mol. Med. , 2017 , 9 , 859-868.

Lenglet, T.; Lacomblez, L.; Abitbol, J.L.; Ludolph, A.; Mora, J.S.; Robberecht, W.; Shaw, P.J.; Pruss, R.M.; Cuvier, V.; Meininger, V.; Mitotarget Study Group. A phase II-III trial of olesoxime in subjects with amyotrophic lateral sclerosis. Eur. J. Neurol. ,2014, 21, 529-536.

Li, W.; Lee, M.H.; Henderson, L.; Tyagi, R.; Bachari, M.; Steiner, J.; Campanac, E.; Hoffman, D.A.; von Gelden, G.; Johnson, K.; Maric, D.; Morris, H.D.; Lentz, M.; Pak, K.; Mammen, A.; Ostrow, L.; Rothstein, J.; Nath, A. Human endogenous retrovirus-K contributes to motor neuron disease. Sci. Transl. Med. , 2015 , 7, ra153.

Liachko, N.F.; McMillan, P.J.; Guthrie, C.R.; Bird, T.D.; Leverenz, J.B.; Kraemer, B.C. CDC7 inhibition blocks pathological TDP-43 phosphorylation and neurodegeneration. Ann. Neurol. ,2013, 74, 39-52.

Libonati, L.; Onesti, E.; Gori, M.C.; Ceccanti, M.; Cambieri, C.; Fabbri, A.; Frasca, V.; Inghilleri, M. Vitamin D in amyotrophic lateral sclerosis. Funct. Neurol. , 2017, 32 , 35-40.

Limpert, A.S.; Mattmann, M.E., Cosford, N.D.P. Recent progress in the discovery of small molecules for the treatment of amyotrophic lateral sclerosis. Beilstein J. Org. Chem., 2013 , 9 , 717-732. 
Ling, K.K.; Jackson, M.; Alkam, D.; Liu, D.; Allaire, N.; Sun, C.; Kiaei, M.; McCampbell, A.; Rigo, F. Antisense-mediated reduction of EphA4 in the adult CNS does not improve the function of mice with amyotrophic lateral sclerosis. Neurobiol. Aging , 2018 ,114 , 174-183.

Liu, C.; Hong, K.; Chen, H.; Niu, Y.; Duan, W.; Liu, Y.; Duan, W.; Liu, Y.; Ji, Y.; Deng, B.; Li, Y.; Li, Z.; Wen, D.; Li, C. Evidence for a protective role of the CX3CL1/CX3CR1 axis in a model of amyotrophic lateral sclerosis. Biol. Chem., 2019 , $400,651-661$.

Lopez-Lopez, A.; Gamez, J.; Syriani, E.; Morales, M.; Salvado, M.; Rodriguez, M.J.; Ma, N.; Vidal-Taboada, J.M. CXC3R1 is a modifying gene of survival and progression in amyotrophic laterals sclerosis.PLoS One, 2014, 9 , e96528.

Lougheed, R.; Turnbul, J. Lack of effect of methylene blue in the SOD1 G93A mouse model of amyotrophic lateral sclerosis. PLoS One ,2011, 6 , e23141.

Macchi, Z.; Wang, Y.; Moore, D.; Katz, J.; Saperstein, D.; Walk, D.; Simpson, E.; Genge, A.; Bertorini, T.; Fernandes, J.A.; Swenson, A.; Elman, L.; Dimachkie, M.; Herbelin, L.; Miller, J.; Lu, J.; Wilkins, H.; Swerdlow, R.H.; Statland, J.; Barohn, R.; Western ALS (WALS) Rasagiline Study Group. A multi-center screening trial of rasagiline in patients with amyotrophic lateral sclerosis: Possible mitochondrial biomarker target engagement. Amyotroph. Lateral Scler. Frontotemporal Degener. , 2015 , 16, 345-352.

Mandrioli, J.; Crippa, V.; Cereda, C.; Bonetto, V.; Zucchi, E.; Gessani, A.; Ceroni, M.; Chio, A.; D' Amico, R.; Monsurrò, M.R.; Riva, N.; Sabatelli, M.; Silani, V.; Simone, I.L.; Sorarù, G.; Provenzani, A.; D' Agostino, V.G.; Carra, S.; Poletti, A. Proteostasis and ALS: protocol for a phase II, randomized, doubleblind, placebo-controlled, multicentre clinical trial for colchicine in ALS (Co-ALS). BMJ Open , 2019 , 9 , e028486.

Mangelsdorf, I.; Walach, H.; Mutter, J. Healing of amyotrophic lateral sclerosis: a case report. Complement Med. Res., 2017 ,24, 175-181.

Marrone, L.; Drexler, H.C.A.; Wang, J.; Tripathi, P.; Distler, T.; Heisterkamp, P.; Anderson, E.N.; Kour, S.; Moraiti, A.; Maharana, S.; Bhatnagar, R.; Belgard, T.G.; Tripathy, V.; Kalmbach, N.; Hosseinzabeh, Z.; Crippa, V.; Abo-Rady, M.; Wegner, F.; Poletti, A.; Troost, D.; Aronica, E.; Busskamp, V.; Weis, J.; Pandey, U.B.; Hyman, A.A.; Alberti, S.; Goswami, A.; Sterneckert, J. FUS pathology in ALS is linked to alterations in multiple ALS-associated proteins and rescued by drugs stimulating autophagy. Acta Neuropathol., 2019 ,138, 67-84.

Matthews, R.T.; Yang, L.; Browne, S.; Baik, M.; Beal, M.F. Coenzyme Q10 administration increases brain mitochondrial concentrations and exerts neuroprotective effects. Proc. Natl. Acad. Sci. USA ,1998, 95 , 8892-8897.

Mayer, J.; Harz, C.; Sanchez, L.; Pereira, G.C.; Maldener, E.; Heras, S.R.; Ostrow, L.W.; Ravits, J.; Batra, R.; Meese, E.; García-Pérez, J.L.; Goodier, J.L. Transcriptional profiling of HERV-K(HML-2) in amyotrophic lateral sclerosis and potential implications for expression of HML-2 proteins. Mol. Neurodegener. , 2018 , 13 , 39 .

Miquel, E.; Cassina, A.; Martínez-Palma, L.; Bolatto, C.; Trías, E.; Gandelman, M.; Radi, R.; Barbeito, L.; Cassina, P. Modulation of astrocytic mitochondrial function by dichloroacetate improves survival and motol performance in inherited amyotrophic lateral sclerosis.PLoS One, 2012, 7 , e34776.

Mitropoulos, K.; Katsila, T.; Patrinos, G.P.; Pampalakis, G. Multi-Omics for Biomarker Discovery and Target Validation in Biofluids for Amyotrophic Lateral Sclerosis Diagnosis. OMICS , 2018 ,22 , 52-64.

Monson, C.S.; Banack, S.A.; Cox, P.A. Conservation implications of Chamorro consumption of flying foxes as a possible cause of amyotrophic lateral sclerosis-parkinsonism dementia complex in Guam. Conserv. Biol. , 2003, 17, 678-686. 
Mori, K.; Arzberger, T.; Grässer, F.A.; Gijselinck, I.; May, S.; Rentzsch, K.; Weng, S.M.; Schludi, M.H.; van der Zee, J.; Cruts, M.; Van Broeckhoven, C.; Kremmer, E.; Kretzschmar, H.A.; Haass, C.; Edbauer, D. Bidirectional transcripts of the expanded C9orf72 hexanucleotide repeat are translated into aggregating dipeptide repeat proteins. Acta Neuropathol. , 2013b , 126 , 881-893.

Mori, K.; Weng, S.M.; Arzberger, T.; May, S.; Rentzsch, K.; Kremmer, E.; Schmid, B.; Kretzschmar, H.A.; Cruts, M.; Van Broeckhoven, C.; Haass, C.; Edbauer, D. The C9orf72 GGGGCC repeat is translated into aggregating dipeptide-repeat proteins in FTLD/ALS. Science, 2013a ,339, 1335-1338.

Moujalled, D.; James, J.L.; Parker, S.J.; Lidgerwood, G.E.; Duncan, C.; Meyerowitz, J.; Nonaka, T.; Hasegawa, M.; Kanninen, K.M.; Grubman, A.; Liddell, J.R.; Crouch, P.J.; White, A.R. Kinase Inhibitor Screening Identifies Cyclin-Dependent Kinases and Glycogen Synthase Kinase 3 as Potential Modulators of TDP-43 Cytosolic Accumulation during Cell Stress. PLoS One, 2013 , 8, e67433.

Neumann, M.; Sampathu. D.M.; Kwong, L.K.; Truax, A.C.; Micsenyi, M.C.; Chou, T.T. Ubiquitinated TDP43 in frontotemporal lobar degeneration and amyotrophic lateral sclerosis. Science, 2006 ,314, 130-133.

Neymotin, A.; Petri, S.; Calingasan, N.Y.; Wille, E.; Schafer, P.; Stewart, C.; Hensley, K.; Beal, M.F.; Kiaei, M. Lenalidomide (Revlimid(R) administration at symptom onset is neuroprotective in a mouse model of amyotrophic lateral sclerosis. Exp. Neurol. , 2009 ,220 , 191-197.

Noberini, R.; Koolpe, M.; Peddibhotla, S.; Dahl, R.; Su, Y.; Cosford, N.D.P.; Roth, G.P.; Pasquale, E.B. Small molecules can selectively inhibit ephrin bind EphA4 and EphA2 receptors. J. Biol. Chem. ,2008, 283 , 29461-29472.

Paganoni, S.; Macklin, E.A.; Hendrix, S.; Berry, J.D.; Elliott, M.A.; Maiser, S.; Karam, C.; Caress, J.B.; Owegi, M.A.; Quick, A.; Wymer, J.; Goutman, S.A.; Heitzman, D.; Heiman-Patterson, T.; Jackson, C.E.; Quinn, C.; Rothstein, J.D.; Kasarskis, E.J.; Katz, J.; Jenkins, L.; Ladha, S.; Miller, T.M.; Scelsa, S.N.; Vu, T.H.; Fournier, C.N.; Glass, J.D.; Johnson, K.M.; Swenson, A.; Goyal, N.A.; Pattee, G.L.; Andres, P.L.; Babu, S.; Chase, M.; Dagostino, D.; Dickson, S.P.; Ellison, N.; Hall, M.; Hendrix, K.; Kittle, G.; McGovern, M.; Ostrow, J.; Pothier, L.; Randall, R.; Shefner, J.M.; Sherman, A.V.; Tustison, E.; Vigneswaran, P.; Walker, J.; Yu, H.; Chan, J.; Wittes, J.; Cohen, J.; Klee, J.; Leslie, K.; Tanzi, R.E., Gilber, W.; Yeramian, P.D.; Schoenfeld, D.; Cudkowicz, M.E. Trial of sodium phenylbutyrate-taurursodiol for amyotrophic lateral sclerosis. New Engl. J. Med. , 2020 ,383 , 919-930.

Palomo, V., Tosat-Bitrian, C.; Nozal, V.; Nagaraj, S.; Martin-Requero, A.; Martinez, A. TDP-43: A Key Therapeutic Target beyond Amyotrophic Lateral Sclerosis. ACS Chem. Neurosci., 2019 , 10 , 1183-1196.

Pampalakis, G.; Mitropoulos, K.; Xiromerisiou, G.; Dardiotis, E.; Deretzi, G.; Anagnostouli, M.; Katsila, T.; Rentzos, M.; Patrinos, G.P. New molecular diagnostic trends and biomarkers for amyotrophic lateral sclerosis. Hum. Mutat. , 2019 , 40 , 361-373.

Petri, S.; Kiaei, M.; Damiano, M.; Hiller, A.; Wille, E.; Manfredi, G.; Calingasan, N.Y.; Szeto, H.H.; Beal, M.F. Cell-permeable peptide antioxidants as a novel therapeutic approach in a mouse model of amyotrophic lateral sclerosis. J. Neurochem., 2006 ,98, 1141-1148.

Polymenidou, M.; Lagier-Tourenne, C.; Hutt, K.R.; Bennett, C.F.; Cleveland, D.W.; Yeo, G.W. Misregulated RNA processing in amyotrophic lateral sclerosis. Brain Res 1462: 3-15.

Posa D, Martínez-González L, Bartolomé F, Nagaraj S, Porras G, Martínez A, Martín-Requero Á. (2019) Recapitulation of Pathological TDP-43 Features in Immortalized Lymphocytes from Sporadic ALS Patients.Mol. Neurobiol. , 2012, 56 , 2424-2432.

Renton, A.E.; Majounie, E.; Waite, A.; Simón-Sánchez, J.; Rollinson, S.; Gibbs, J.R.; Schymick, J.C.; Laaksovirta, H.; van Swieten, J.C.; Myllykangas, L.; Kalimo, H.; Paetau, A.; Abramzon, Y.; Remes, A.M.; Kaganovich, A.; Scholz, S.W.; Duckworth, J.; Ding, J.; Harmer, D.W.; Hernandez, D.G.; Johnson, J.O.; Mok, K.; Ryten, M.; Trabzuni, D.; Guerreiro, R.J.; Orrell, R.W.; Neal, J.; Murray, A.; Pearson, J.; Jansen, I.E.; 
Sondervan, D.; Seelaar, H.; Blake, D.; Young, K.; Halliwell, N.; Callister, J.B.; Toulson, G.; Richardson, A.; Gerhard, A.; Snowden, J.; Mann, D.; Neary, D.; Nalls, M.A.; Peuralinna, T.; Jansson, L.; Isoviita, V.M.; Kaivorinne, A.L.; Hölttä-Vuori, M.; Ikonen, E.; Sulkava, R.; Benatar, M.; Wuu, J.; Chiò, A.; Restagno, G.; Borghero, G.; Sabatelli, M; ITALSGEN Consortium; Heckerman, D.; Rogaeva, E.; Zinman, L.; Rothstein, J.D.; Sendtner, M.; Drepper, C.; Eichler, E.E.; Alkan, C.; Abdullaev, Z.; Pack, S.D.; Dutra, A.; Pak, E.; Hardy, J.; Singleton, A.; Williams, N.M.; Heutink, P.; Pickering-Brown, S.; Morris, H.R.; Tienari, P.J.; Traynor, B.J. A hexanucleotide repeat expansion in C9ORF72 is the cause of chromosome 9p21-linked ALS-FTD. Neuron ,2011, 72 , 257-268.

Roberts, B.R.; Lim, N.K.H.; McAllum, E.J.; Donnely, P.S.; Hare, D.J.; Doble, P.A.; Turner, B.J.; Price, K.A.; Lim, S.C.; Paterson, B.M.; Hickey, J.L.; Rhoads, T.W.; Williams, J.R.; Kanninen, K.M.; Hung, L.W.; Liddell, J.R.; Grubman, A.; Monty, J.F.; Llanos, R.M.; Kramer, D.R.; Mercer, J.F.B.; Bush, A.I.; Masters, C.L.; Duce, J.A.; Li, Q.X.; Beckman, J.S.; Barnham, K.J.; White, A.R.; Crouch, P.J. Oral treatment with $\mathrm{Cu}(\mathrm{II})(\mathrm{atsm})$ increases mutant SOD1 in vivo but protects motor neurons and improves the phenotype of a transgenic mouse model of amyotrophic lateral sclerosis. J. Neurosci. , 2014 ,34 , 8021-8031.

Roos, P.M.; Vesterberg, O.; Syversen, T.; Flaten, T.P.; Nordberg, M. Metal concentrations in cerebrospinal fluid and blood plasma form patients with amyotrophic lateral sclerosis. Biol. Trace Elem. Res.,2014 , 151 , 159-170.

Rösener, M.; Hahn, H.; Kranz, M.; Heeney, J.; Rethwilm, A. Absence of serological evidence for foamy virus infection in patients with amyotrophic lateral sclerosis. J. Med. Virol. , 1998 ,48 , 222-226.

Rothstein, J.D.; Patel, S.; Regan, M.R.; Haenggeli, C.; Huang, Y.H.; Bergles, D.E.; Jin, L.; Hoberg, M.D.; Vidensky, S.; Chung, D.S.; Toan, S.V.; Bruijn, L.I.; Su, Z.Z.; Gupta, P.; Fischer, P.B. Beta-lactam antibiotics offer neuroprotection by increasing glutamate transporter expression. Nature, 2005 , 433 , 73-77.

Rue, L.; Timmers, M.; Lenaerts, A.; Smolders, S.; Poppe, L.; de Boer, A.; Van Den Bosch, L.; Van Damme, P.; Robberecht, W.; Lemmens, R. Reducing EphA4 before disease onset does not affect survival in a mouse model of Amyotrophic Lateral Sclerosis. Sci. Rep. , 2019 ,9 , 14112.

Ryu, H.H.; Jun, M.H.; Min, K.J.; Jang, D.J.; Lee, Y.S.; Kim, H.K. Autophagy regulates amyotrophic lateral sclerosis-linked fused in sarcoma-positive stress granules in neurons. Neurobiol. Aging ,2014 , 35, 2822-2831.

Salado, I.G.; Redondo, M.; Bello, M.L. Protein kinase CK-1 inhibitors as new potential drugs for amyotrophic lateral sclerosis. J. Med. Chem. , 2014, 57 , 275-2772.

Simone, R.; Balendra, R.; Moens, T.G.; Preza, E.; Wilson, K.M.; Heslegrave, A.; Woodling, N.S.; Niccoli, T.; Gilbert-Jaramillo, J.; Abdelkarim, S.; Clayton, E.L.; Clarke, M.; Konrad, M.T.; Nicoll, A.J.; Mitchell, J.S.; Calvo, A.; Chio, A.; Houlden, H.; Polke, J.M.; Ismail, M.A.; Stephens, C.E.; Vo, T.; Farahat, A.A.; Wilson, W.D.; Boykin, D.W.; Zetterberg, H.; Partridge, L.; Wray, S.; Parkinson, G.; Neidle, S.; Patani, R.; Fratta, P.; Isaacs, A.M. G-quadruplex-binding small molecules ameliorate C9orf72 FTD/ALS pathology in vitro and in vivo.EMBO Mol. Med. , $2018,10,22-31$.

Smith, L.G. Improvement of patient with amyotrophic laterals sclerosis given ceftriaxone. Lancet, 1992 , $339,1417$.

Soo, K.Y.; Halloran, M.; Sundaramoorthy, V.; Parakh, S.; Toth, R.P.; Southam, K.A.; McLean, C.A., Lock, P.; King, A.; Farg, M.A.; Atkin, J.D. Rab1-dependent ER-Golgi transport dysfunction is a common pathogenic mechanism in SOD1, TDP-43 and FUS-associated ALS. Acta Neuropathol., 2015 , 130 , 679-697.

Spiller, K.J.; Khan, T.; Dominique, M.A.; Restrepo, C.R.; Cotton-Samuel, D.; Levitan, M.; Jafar-Nejad, P.; Zhang, B.; Soriano, A.; Rigo, F.; Trojanowski, J.Q.; Lee, V.M. Reduction of matrix metalloproteinase 9 (MMP-9) protects motor neurons from TDP-43-triggered death in rNLS8 mice. Neurobiol. Dis. , 2019 , 124 , 133-140.

Staats, K.A.; Sea, H.C.; Sahimi, A.; Wang, Y.; Koutsodendris, N.; Lin, S.; Kim, D.; Chang, W.H.; Gray, 
K.A.; Shi, Y.; Li, Y.; Chateau, M.; Vangoor, V.R.; Senthilkumar, K.; Pasterkamp, R.J.; Cannon, P.; Zlokovic, B.V.; Ichida, J.K. Small molecule inhibition of PIKFYVE kinase rescues gain- and loss-of-function C9ORF72 ALS/FTD disease processes in vivo.bioRxiv , 2019, 685800 .

Stommel, E.W.; Cohen, J.A.; Fadul, C.E.; Cogbill, C.H.; Graber, D.J.; Kingman, L.; Mackenzie, T.; Channon Smith, J.Y.; Harris, B.T. Efficacy of thalidomide for the treatment of amyotrophic lateral sclerosis: a phase II open label clinical trial. Amyotroph. Lateral Scler. ,2009 , 10 , 5-6.

Su, X.W.; Nandar, W.; Neely, E.B.; Simmons, Z.; Connor, J.R. Statins accelerate disease progression and shorten survival in SOD1 mice.Muscle Nerve, 2016 , 54, 284-291.

Su, Z.; Zhang, Y.; Gendron, T.F.; Bauer, P.O.; Chew, J.; Yang, W.Y.; Fostvedt. E.; Jansen-West, K.; Belzil, V.V.; Desaro, P.; Johnston, A.; Overstreet, K.; Oh, S.Y.; Todd, P.K.; Berry, J.D.; Cudkowicz, M.E.; Boeve, B.F.; Dickson, D.; Floeter, M.K.; Traynor, B.J.; Morelli, C.; Ratti, A.; Silani, V.; Rademakers, R.; Brown, R.H.; Rothstein, J.D.; Boylan, K.B.; Petrucelli, L.; Disney, M.D. Discovery of a biomarker and lead small molecules to target r(GGGGCC)-associated defects in c9FTD/ALS. Neuron, 2014, 83, 1043-1050.

Sunyach, C.; Michaud, M.; Arnoux, T.; Bernard-Marissal, N.; Aebischer, J.; Latyszenok, V.; Gouarné, C.; Raoul C; Pruss, R.M.; Bordet, T.; Pettmann, B. Olesoxime delays muscle denervation, astrogliosis, microglial activation and motoneuron death in an ALS mouse model.Neuropharmacology , 2012, 62 , 2346-2352.

Swinnen, B.; Robberecht, W. The phenotypic variability of amyotrophic lateral sclerosis. Nat. Rev. Neurol. , $2014,10,661-670$.

Tian, K.W.; Jiang, H.; Wang, B.B.; Zhang, F.; Han, S. Intravenous injection of l-BMAA induces a rat model with comprehensive characteristics of amyotrophic lateral sclerosis/Parkinson-dementia complex. Toxicol. Res. (Camb) , 2015, 5 , 79-96.

Trippier, P.C.; Zhao, K.T.; Fox, S.G.; Schiefer, I.T.; Benmohamed, R.; Moran, J.; Kirsch, D.R.; Morimoto, R.I.; Silverman, R.B. Proteasome activation is a mechanism for pyrazolone small molecules displaying therapeutic potential in amyotrophic lateral sclerosis. ACS Chem. Neurosci. , 2014 , 5 , 823-829.

Trojsi, F.; Siciliano, M.; Passaniti, C.; Bisecco, A.; Russo, A.; Lavorgna, L.; Esposito, S.; Ricciardi, D.; Monsurrò, M.R.; Tedeschi, G.; Santangelo, G. Vitamin D supplementation has no effects on progression of motor dysfunction in amyotrophic lateral sclerosis (ALS). Eur. J. Clin. Nutr., 2020 , 74, 167-175.

Tsuburaya, N.; Homma, K.; Higuchi, T.; Balia, A.; Yamakoshi, H.; Shibata, N.; Nakamura, S.; Nakagawa, H.; Ikeda, S.; Umezawa, N.; Kato, N.; Yokoshima, S.; Shibuya, M.; Shimonishi, M.; Kojima, H.; Okabe, T.; Nagano, T.; Naguro, I.; Imamura, K.; Inoue, H.; Fujisawa, T.; Ichijo, H. A small-molecule inhibitor of SOD1-Derlin 1 ameliorates pathology in an ALS mouse model. Nat. Commun., 2018 , 9 , 2668.

Tyagi, R.; Li, W.; Parades, D.; Bianchet, M.A.; Nath, A. Inhibition of human endogenous retrovirus-K by antiretroviral drugs.Retrovirology , 2017 , 14, 21.

Vaccaro, A.; Patten, S.A.; Ciura, S.; Maios, C.; Therrien, M.; Drapau, P.; Kabashi, E.; Parker, J.A. Methylene blue protects against TDP-43 and FUS neuronal toxicity in C. elegans and D. rerio .PLOS One, 2012, 7 , e42117.

Van Eijk, R.P.A.; Eijkemans, M.J.C.; Nikolakopoulos, S.; Jansen, M.D.; Westeneng, H.J.; van Eijk, K.R.; van der Spek, R.A.A.; van Vugt, J.J.F.A.; Piepers, S.; Groeneveld, G.J.; Veldink, J.H.; van den Berg, L.H.; van Es, M.A. Pharmacogenetic interactions in amyotrophic lateral sclerosis: a step closer to a cure? Pharmacogenomics J. ,2019 , 20 , 220-226.

Van Eijk, R.P.A.; Jones, A.R.; Sproviero, W.; Shatunov, A.; Shaw, P.J.; Leigh, P.N.; Young, C.A.; Shaw, C.E.; Mora, G.; Mandrioti, J.; Borghero, G.; Volanti, P.; Diekstra, F.P.; van Rheenen, W.; Verstraete, E.; Eijkemans, M.J.C.; Veldink, J.H.; Chio, A.; Al-Chalabi, A.; van den Berg, L.H.; van Es, M.A.; For UKMNDLiCALS and LITALS study group. Meta-analysis of pharmacogenetic interactions in amyotrophic lateral sclerosis clinical trials. Neurology , 2017, 89, 1915-1922. 
Van Hoecke, A.; Schoonaert, L.; Lemmens, R.; Timmers, M.; Staats, K.A.; Laird, A.S.; Peeters, E.; Philips, T.; Goris, A.; Dubois, B.; Andersen, P.M.; Al-Chalabi, A.; Thinjs, V.; Turnley, A.M.; van Vught, P.W.; Veldink, J.H.; Hardiman, O.; Van Den Bosch. L.; Gonzalez-Perez, P.; Van Damme, P.; Brown, JR. R.H.; van den Berg, L.H.; Robberecht, W. EPHA4 is a disease modifier of amyotrophic lateral sclerosis in animal models and in humans. Nat. Med. , 2012, 18 , 1418-1422.

Vidal-Taboada, J.M.; Pugliese, M.; Salvadó, M.; Gámez, J.; Mahy, N.; Rodríguez, M.J. K AtP channel expression and genetic polymorphisms associated with progression and survival in amyotrophic lateral sclerosis. Mol. Neurobiol. , 2018 , 55 , 7962-7972.

Waibel, S.; Reuter, A.; Malessa, S.; Blaugrund, E.; Ludolph, A.C. Rasagiline alone and in combination with riluzole prolongs survival in an ALS mouse model. J. Neurol. , 2004 , 251 , 1080-1084.

Wang, I.F.; Guo, B.S.; Liu, Y.C. Autophagy activators rescue and alleviate pathogenesis of a mouse model with proteinopathies of the TAR DNA-binding protein 43. Proc. Natl. Acad. Sci. USA ,2012, 109 , 1502415029 .

Wang, Z.F.; Ursu, A.; Childs-Disney, J.L.; Guertler, R.; Yang, W.Y.; Bernat, V.; Rzuczek, S.G.; Fuerst, R.; Zhang, Y.J.; Gendron, T.F.; Yildirim, I.; Dwyer, B.G.; Rice, J.E.; Petrucelli, L.; Disney, M.D. The Hairpin Form of $\mathrm{r}(\mathrm{G}(4) \mathrm{C}(2))(\mathrm{exp})$ in c9ALS/FTD Is Repeat-Associated Non-ATG Translated and a Target for Bioactive Small Molecules.Cell Chem. Biol. , 2019, 26 , 179-190.e12.

Westarp, M.E.; Bartmann, P.; Rossler, J.; Geiger, E.; Westphal, K.P.; Schreiber, H.; Fuchs, D.; Westarp, M.P.; Kornhuber, H.H. Antiretroviral therapy in sporadic adult amyotrophic lateral sclerosis.Neuroreport , $1993,4,819-822$.

Wilkins, H.M.; Morris, J.K. New Therapeutics to Modulate Mitochondrial Function in Neurodegenerative Disorders. Curr. Pharm. Des. ,2017, 23, 731-752.

Wosiski-Kuhn, M.; Robinson, M.; Strupe, J.; Arounleut, P.; Martin, M.; Caress, J.; Cartwright, M.; Bower, R.; Cudkowicz, M.; Langefeld, C.; Hawkins, G.A.; Milligan, C. IL6 receptor ${ }^{358}$ Ala variant and trans-signaling disease modifiers in amyotrophic lateral sclerosis. Neurol. Neuroimmunol. Neuroinflamm. , 2019 ,6 , e631.

Wu, B., De, S.K.; Kulinich, A.; Salem, A.F.; Koeppen, J.; Wang, R.; Barile, E.; Wang, S.; Zhang, D.; Ethell, I.; Pellecchia, M. Potent and Selective EphA4 Agonists for the Treatment of ALS. Cell Chem. Biol. , 2017 , $24,293-305$.

Xia, Q.; Wang, H.; Hao, Z. TDP-43 loss of function increases TFEB activity and blocks autophagosomelysosome fusion. EMBO J.,2016, $35,121-142$.

Xiao, S.; Sanelli, T.; Dib, S. RNA targets of TDP-43 identified by UV-CLIP are deregulated in ALS. Mol. Cell. Neurosci., $2011,47,167-180$.

Yanagi, K.S.; Wu, Z.; Amaya, J.; Chapkis, N.; Duffy, A.M.; Hajdarovic, K.; Held, A.; Mathur, A.D.; Russo, K.; Ryan, V.H.; Steinert, B.L.; Whitt, J.P.; Fallon, J.R.; Fawzi, N.L.; Lipscombe, D.; Reenan, R.A.; Wharton, K.A.; Hart, A.C. Meta-analysis of genetic modifiers reveals candidate dysregulated pathways in Amyotrophic Lateral Sclerosis.Neuroscience, 2019 , 396 , A3-A20.

Zamiri, B.; Reddy, K.; Macgregor, R.B. Jr.; Pearson, C.E. TMPyP4 porphyrin distorts RNA G-quadruplex structures of the disease-associated $\mathrm{r}(\mathrm{GGGGCC}) \mathrm{n}$ repeat of the C9orf72 gene and blocks interaction of RNA-binding proteins. J. Biol. Chem., 2014, 289 , 4653-4659.

Zarogoulidis, P.; Lampaki, S.; Turner, J.F. mTOR pathway: A current, up-to-date mini-review. Oncol. Lett. , 2014, $8,2367-2370$.

Zhang, X., Li, L.; Chen, S.; Yang, D.; Wang, Y.; Zhang, X.; Wang, Z.; Le, W. Rapamycin treatment augments motor neuron degeneration in SOD1(G93A) mouse model of amyotrophic lateral sclerosis.Autophagy, 2011 $, 7,412-25$. 
Zhang, Y.; Zhao, K.T.; Fox, S.G.; Kim, J.; Kirsch, D.R.; Ferrante, R.J.; Morimoto, R.I.; Silverman, R.B. Tertiary amine pyrazolones and their salts as inhibitors of mutant superoxide dismutase 1-dependent protein aggregation for the treatment of amyotrophic lateral sclerosis. J. Med. Chem. , 2015 , 58 , 5942-5949.

Zhang, Y.J.; Jansen-West, K.; Xu, Y.F.; Gendron, T.F.; Bieniek, K.F.; Lin, W.L.; Sasaguri, H.; Caulfield, T.; Hubbard, J.; Daughrity, L.; Chew, J.; Belzil, V.V.; Prudencio, M.; Stankowski, J.N.; Castanedes-Casey, M.; Whitelaw, E.; Ash, P.E.; DeTure, M.; Rademakers, R.; Boylan, K.B.; Dickson, D.W.; Petrucelli, L. Aggregation-prone c9FTD/ALS poly(GA) RAN-translated proteins cause neurotoxicity by inducing ER stress. Acta Neuropathol., 2014 , 128 , 505-524.

Zhou, Q.; Mareljic, N.; Michaelsen, M.; Parhizkar, S.; Heindl, S.; Nuscher, B.; Farny, D.; Czuppa, M.; Schludi, C.; Graf, A.; Krebs, S.; Blum, H.; Feederle, R.; Roth, S.; Haass, C.; Arzberger, T.; Liesz, A.; Edbauer, D. Active poly-GA vaccination prevents microglia activation and motor deficits in a C9orf72 mouse model. EMBO Mol. Med. ,2020, 12, e10919.

Zinman, L.; Sadeghi, R.; Gawel, M.; Patton, D.; Kiss, A. Are statin medications safe in patients with ALS? Amyotroph. Lateral Scler. ,2008, 9 , 223-228.

Zoing, M.C.; Burke, D.; Pamphlett, R. Riluzole therapy for motor neurone disease: An early Australian experience (1996-2002). J. Clin. Neurosci., 2006 , 13, 78-83.

Zou, Z.Y.; Zhou, Z.R.; Che, C.H.; Liu, C.Y.; He, R.L.; Huang, H.P. Genetic epidemiology of amyotrophic lateral sclerosis: a systematic review and meta-analysis. J. Neurol. Neurosurg. Psychiatry ,2017 , 88, 540-549

Zu, T.; Guo, S.; Bardhi, O.; Ryskamp, D.A.; Li, J.; Tusi, S.K.; Engelbrecht, A.; Klippel, K.; Chakrabarty, P.; Nguyen, L.; Golde, T.E.; Sonenberg, N.; Ranum, L.P.W. Metformin inhibits RAN translation through PKR pathway and mitigates disease in C9ORF72 ALS/FTD mice. Proc. Natl. Acad. Sci. USA, 2020, 117 , 18591-18599.

\section{Hosted file}

Figure 1.pptx available at https://authorea.com/users/392584/articles/506392-a-chemogenomicapproach-seems-indispensable-for-effective-treatment-of-amyotrophic-lateral-sclerosis

\section{Hosted file}

Chemical formulas.pptx available at https://authorea.com/users/392584/articles/506392a-chemogenomic-approach-seems-indispensable-for-effective-treatment-of-amyotrophiclateral-sclerosis 